\title{
ACE

\section{TRANSFORMACIONES DE LA CIUDAD Y EL SHOPPING CENTER - ANÁLISIS EN LA ESCALA DEL SECTOR DE IÑAQUITO Y EL QUICENTRO SHOPPING CENTER EN QUITO}

Daniela Sofía Loaiza Jiménez

Cómo citar este artículo: LOAIZA JIMÉNEZ, D. S. Transformaciones de la ciudad y el shopping center - Análisis en la escala del sector de Iñaquito y el Quicentro Shopping Center en Quito [en línea] Fecha de consulta: dd-mm-aa. En: ACE: Architecture, City and Environment, 14 (40): 297-315, 2019. DOI: http://dx.doi.org/10.5821/ace.14.40.5400 ISSN: 1886-4805.

\section{Architecture, City, and Environment




\section{ACE 40}

Electronic offprint

Separata electrónica

\section{TRANSFORMATIONS OF THE CITY AND THE SHOPPING CENTER - ANALYSIS IN THE SCALE OF THE QUICENTRO SHOPPING AND THE IÑAQUITO SECTOR IN QUITO}

Key words: shopping center; conceived space; built space; lived space; urban planning

\section{Structured abstract}

Objective

Literature shows different theoretical positions regarding modifications caused by shopping centers in the urban structure. There is an approximation that accuses them to be a threat to the city, while others acclaim these to be an opportunity. The objective of this analysis is to understand the role that this shopping center plays in the city.

\section{Methodology}

This article will address the abovementioned two different perspectives by discussing the Quicentro Shopping Center, located in Quito - Ecuador, graphically analyzing the city between 1970 and 2015 from the social space trialectic; planned or conceived space, perceived or constructed space, and lived or appropriated space (Lipovetsky $2007,2006)$, in the scale of the Quicentro Shopping and the Iñaquito sector; scope where it is inserted.

\section{Conclusions}

The shopping centers are a phenomena that do not always constitute closed and disarticulated boxes of their environment, but permeable elements that are linked to the city and are used as urban development and reactivation components.

\section{Originality}

There is no extensive research on shopping centers using this approach, so it will be a methodological tool for the analysis and planning of other shopping centers that are linked to the city, before or after being inserted.

\section{ACE




\section{TRANSFORMACIONES DE LA CIUDAD Y EL SHOPPING CENTER - ANÁLISIS EN LA ESCALA DEL SECTOR DE IÑAQUITO Y EL QUICENTRO SHOPPING CENTER EN QUITO}

\section{LOAIZA JIMÉNEZ, Daniela Sofía ${ }^{1}$}

Remisión inicial: $22-01-2018$

Aceptación inicial: 10-03-2018

Remisión final: 24-03-2019

Aceptación definitiva: 25-03-2019

Palabras clave: shopping center; espacio concebido; espacio construido; espacio vivido; planificación urbana

\section{Resumen estructurado}

\section{Objetivo}

La literatura sobre los shopping centers muestra diferentes posiciones teóricas en relación a las modificaciones que provocan en la estructura urbana. Existe una aproximación que lo acusa de ser una amenaza para la ciudad, mientras otras corrientes lo defienden como una oportunidad. Con este análisis se pretende entender el rol que desempeña el shopping center en la ciudad,

\section{Metodología}

Se abordará la discusión del Quicentro Shopping Center (en la ciudad de Quito, Ecuador) desde estas las dos perspectivas mencionadas, analizando gráficamente a la ciudad entre 1970 y 2015 , desde la trialéctica del espacio social -el espacio concebido o planificado, el percibido o construido y el vivido o apropiado (Lipovetsky 2007, 2006), en escala del Quicentro Shopping y el sector de Iñaquito; ámbito donde está insertado.

\section{Conclusiones}

Los shopping centers son fenómenos que no siempre constituyen cajas cerradas y desarticuladas de su entorno, sino elementos permeables que se enlazan con la ciudad y son utilizados como componentes para el desarrollo y la reactivación urbana.

\section{Originalidad}

No existe una investigación amplia acerca de los shopping centers desde esta aproximación, por lo que será una herramienta metodológica para el análisis y planificación, de otros shopping centers que se enlacen con la ciudad, previa o posterior a su inserción.

\footnotetext{
1 Dra. en Arquitectura y Urbanismo. Universidad de Bío Bío /Chile. Miembro del Núcleo de Investigación en Configuración Morfológica en la Arquitectura y el Urbanismo / UFSC / Brasil. Docente de titulación en la Universidad de las Américas / Quito. Correo electrónico: loaizadaniela@gmail.com
}

ACE@ AÑO 14, núm. 40, JUNIO 2019 | TRANSFORMACIONES DE LA CIUDAD Y EL SHOPPING CENTER - ANÁLISIS EN LA ESCALA 297 


\section{Introducción}

El shopping center surge como una nueva tipología arquitectónica y urbanística (Bell, 2006) de gran almacén a mediados del siglo XX. Su expansión y proliferación ha venido colonizando los suburbios, los asentamientos satélites residenciales y también los centros tradicionales de las ciudades con su discurso de ser el nuevo envolvente de la vida urbana y de fomentar y fortalecer la sociabilidad, la vida colectiva y el encuentro (Lipovetsky, 2007, 2006).

La emergente sociedad posindustrial, ha sido descrita como una sociedad que tiene un deseo incontrolable de satisfacer sus necesidades y deseos, los cuales se manifiestan y materializan espacialmente en las ciudades. En consecuencia, el shopping center surge como una respuesta a esta sociedad y se convierte en un nuevo elemento urbanístico que detona dinámicas, situaciones y lógicas en las ciudades, gana espacio sobre los centros tradicionales y empieza a estructurar la vida colectiva en las periferias norteamericanas (Bell, 2006).

La producción artesanal ha sido remplazada por la producción masiva del retail y se ha constituido como un elemento fundamental de la vida cotidiana, fortaleciéndose como base estructural de la vida colectiva (Lipovetsky, 2007). Así, la vida misma gira en torno al ocio, al entretenimiento y al consumo.

El shopping center fue concebido en período de posguerra como un nuevo centro, un nuevo espacio que estructuraba el encuentro colectivo y la sociabilidad, un espacio incrustado en las periferias residenciales de los suburbios norteamericanos donde el acceso era posible únicamente con vehículo particular (Bell, 2006). Con la facilidad de acceso a la compra de vehículos y viviendas en las periferias en la época, los centros tradicionales empiezan a perder su jerarquía en la estructura espacial de las ciudades. Así, el shopping center materializó espacialmente las lógicas del mercado y de los grandes operadores privados (Dupuy, 1998), asignando el valor del suelo, la densidad, el acceso, sus usos, las formas de ocupación y la edificabilidad.

En la literatura académica sobre el shopping center, existen discusiones y debates acerca de las transformaciones espaciales y comportamentales provocadas por su inserción en las ciudades. Existe una corriente que acusa al shopping center de aniquilar el espacio público al introducir las actividades urbanísticas cotidianas dentro de un objeto que desarrolla su vida desde sus muros hacia el interior. Esta corriente lo presenta también como uno de los responsables del "urban sprawl" y de la desertificación de los centros históricos.

Otra corriente, contraria a la anterior ${ }_{2}$ argumenta que el shopping center produce un efecto de renovación y transformación positiva del espacio urbano, fortaleciendo las dinámicas del espacio público. Lo presentan como una plataforma de sociabilidad e intercambio la cual puede ser modificada y transformada por sus usuarios de acuerdo a la velocidad de evolución de sus necesidades, facilitando la transposición de actividades e incentivando la diversidad programática y morfológica.

Se entrará con mayor detalle y precisión en la literatura de estas dos corrientes enunciadas para conformar el marco teórico de este artículo.

ACE@ AÑO 14, núm. 40, JUNIO 2019 | TRANSFORMACIONES DE LA CIUDAD Y EL SHOPPING CENTER - ANÁLISIS EN LA ESCALA 298 
Se presentará al Quicentro Shopping Center (QSC) como estudio de caso en la ciudad de Quito - Ecuador, y se realizará el análisis, en escala del sector donde está insertado, del espacio concebido, construido y vivido (Lefebvre, 2000) en diferentes períodos (antes, durante y después de su inserción en la ciudad). Las variables analizadas serán: uso de suelo, transporte, densidad, edificabilidad/zonificación. Estas variables permitirán evidenciar el grado de diversidad que existe en el espacio urbano inmediato al QSC desde su planificación y materialización.

Este artículo complementa investigaciones (Autor, 2016, 2017) donde se analiza al Quicentro Shopping Center desde el espacio concebido y construido en la escala de la ciudad de Quito y en la escala de su entorno inmediato.

A manera de conclusión, serán presentadas consideraciones finales con algunos comentarios y cuestionamientos que puedan aportar al desarrollo de futuras investigaciones.

\section{Hipótesis, objetivos, metodología y estructura de la investigación}

Al constituir el shopping center una tipología de escala urbanístico-arquitectónica asociada estrechamente con el debilitamiento del rol del espacio público, con la transformación de las formas de vida y con el consumo de masas, es fundamental aquí estudiar las transformaciones morfológicas, el reordenamiento de usos y la diversas formas de apropiación que han venido ocurriendo en paralelo a su inserción en la ciudad. Es importante comprender, desde esta perspectiva, la relación que existe entre el shopping center y la ciudad, ligada a las necesidades sociales que son las que transforman el espacio y que, a la vez, son transformadas por él.

Para ello es fundamental analizar el rol del shopping en la estructura espacial de las ciudades contemporáneas, para lo cual se ha seleccionado al Quicentro Shopping Center de la ciudad de Quito, en Ecuador, como un caso que reúne variables de carácter social, cultural, simbólico, económico y político que pueden aportar al estudio de estas arquitecturas en el contexto latinoamericano.

Con base en estas reflexiones, se han planteado los siguientes cuestionamientos para el desarrollo de esta investigación:

1. ¿Son siempre los shopping centers, burbujas cerradas que niegan la ciudad desde su planificación, construcción y apropiación?

2. ¿Pueden ser los shopping centers detonantes que incentiven la vitalidad de la ciudad?

En aras de responder estas preguntas y llevar a cabo esta investigación se ha planteado la siguiente hipótesis:

No siempre los shopping centers son cajas cerradas, desarticuladas de su entorno. Por el contrario, pueden ser elementos permeables, enlazados con la ciudad, que pueden utilizarse como base de desarrollo y reactivación urbana, para fortalecer la centralidad y vitalidad en las ciudades. Así, existe una estrecha relación entre la planificación, la construcción y la vivencia

ACE@ AÑO 14, núm. 40, JUNIO 2019 | TRANSFORMACIONES DE LA CIUDAD Y EL SHOPPING CENTER - ANÁLISIS EN LA ESCALA 299 DEL SECTOR DE IÑAQUITO Y EL QUICENTRO SHOPPING CENTER EN QUITO 
del QSC, y las transformaciones morfológicas y el reordenamiento de usos en el sector donde se inserta.

Durante de la crisis económica de los años 80 en el Ecuador, ante el evidente abandono de los espacios públicos de la ciudad de Quito (Carrión, 2010), tanto por parte del gobierno local, como de sus usuarios, unos promotores privados impulsaron la construcción de un equipamiento comercial de gran magnitud (Quicentro Shopping Center), en una zona pericentral de la ciudad. Esto generó determinadas repercusiones, y no solamente en la forma en la que se desarrolló la ciudad y en la manera en que esta fue apropiada, sino también en el modo de planificar espacios urbanos diversos, resultando el shopping center un modelo de desarrollo y reactivación urbana dada la concentración de actividades y de personas en búsqueda de la satisfacción de necesidades comerciales, de encuentro, de ocio y entretenimiento.

Para poner a prueba esta hipótesis, se ha considerado muy apropiado estudiar al Quicentro Shopping Center, al tratarse de un complejo comercial levantado en 1982 en un terreno calificado como comercial, en un sector pericentral de la ciudad, concebido como centro financiero de la capital. Desde su origen se plantea como una arquitectura permeable que favorece la relación con la ciudad. Hoy, el sector donde se encuentra el Quicentro tiene un alto grado de centralidad al ser el centro financiero, administrativo, de recreación y ocio de Quito.

Es importante resaltar que, en la ciudad de Quito, y en general en el Ecuador, la discusión sobre los shopping centers a nivel científico o académico aún no ha sido un tema de profunda preocupación o reflexión. Más bien, el debate se ha centrado en la repetición de los discursos "apocalípticos" (Napadensky, 2015) que lo sugieren como un espacio genérico y cerrado que niega la ciudad y que pertenece únicamente a una sociedad individualista de élite, sin considerar o incorporar al análisis a una variedad de grupos sociales que se vinculan a estos centros comerciales, ni a los fenómenos que éstos suscitan en diversas escalas.

Por eso, se ha abordado esta investigación desde dos aproximaciones opuestas que otorgan el marco para comprender las diferentes perspectivas del objeto de estudio: el shopping center como amenaza y el shopping center como oportunidad.

Para poder estudiar la planificación, construcción y apropiación de la ciudad se ha considerado como eje fundamental el proceso metodológico desarrollado por Napadensky $(2015 ; 2012)$ desde el enfoque planteado por Lefebvre (2000) y posteriormente ampliado por Soja (2000) donde se clasifica el espacio social en tres componentes: el concebido o planificado, el percibido o construido y el vivido o apropiado.

1. El espacio concebido o planificado, que se refiere a una representación o expresión abstracta, simbólica e imaginaria de un espacio, a una primera noción o idea de lo que el espacio debe ser, un plan o un germen de proyecto.

2. El espacio percibido o construido, definido como el espacio físico, material o tangible. Todo lo que los ojos alcanzan a ver y lo que se puede percibir a través de los sentidos.

3. El espacio vivido o apropiado, que fue profundizado por Soja (2000) como un espacio donde lo concebido y lo percibido actúan simultáneamente e incorporan la experiencia del lugar,

ACEO AÑo 14, núm. 40, JUNIO 2019 | TRANSFORMACIONES DE LA CIUDAD Y EL SHOPPING CENTER - ANÁLISIS EN LA ESCALA 300 DEL SECTOR DE IÑAQUITO Y EL QUICENTRO SHOPPING CENTER EN QUITO 
sus diferentes formas de apropiación, las diferentes maneras de volver suyo el espacio y ocuparlo.

Con el fin de evidenciar y responder a la hipótesis general de la tesis se analizaron gráficamente 4 variables espaciales cuantitativas: Uso de suelo, densidad, transporte y edificabilidad/zonificación, que sirvieron como indicadores de centralidad (Santos y Voguel, 1985; Panerai, 2006; Ellin, 2006; Hassenpflug, 2007; Bento, 2011); intensidad, concentración y diversidad de usos, usuarios, horarios situaciones y actividades.

Alineado a esto, se considera como la primera variable cuantitativa al uso de suelo, la cual constatará la concentración de uso de suelo múltiple, la concentración de equipamientos y de espacios públicos planificados y efectivamente construidos. La segunda es el transporte, la cual permitirá localizar los puntos de mayor accesibilidad y conectividad de la ciudad. La tercera es la densidad con la que se obtendrá datos de concentración de población. La cuarta es la edificabilidad/zonificación, que hará posible evidenciar las diferentes alturas, y formas de ocupación de la zona de estudio. Al final del análisis de estas 4 variables, se podrá evidenciar el grado de centralidad que tiene el sector donde se inserta el QSC.

En relación a la selección de estas 4 variables seleccionadas, es importante resaltar que según los autores Santos y Vogel (1985), la coexistencia de una adecuada densidad, de diversos usos y formas, configurando los espacios urbanos, permiten una variedad de actividades y hacen del lugar un espacio atractivo que posibilita un alto grado de apropiación (Vidal y Pol, 2005). La diversidad de formas permite, asimismo, la variedad de usos (Brandão, 2002), los cuales, en palabras de la autora Nan Ellin (2006), incentivan a la "salud" y bienestar de los lugares al ser plataformas de variadas actividades, organizaciones, ideas, finalidades, usuarios y horarios en el espacio urbano, facilitando la apropiación de la ciudad (Vidal y Pol, 2005).

A partir de este análisis gráfico, se podrán establecer las efectivas relaciones que pueden existir entre la planificación, construcción y apropiación del shopping center y la ciudad.

En definitiva, esta investigación se estructura de la siguiente manera:

1. El presente primer capítulo presenta las preguntas de investigación, hipótesis y objetivo general, a partir de los cuales se justifica el proceso metodológico y el caso de estudio de esta investigación.

2. El segundo capítulo representa el marco y discusión teórica entre las dos aproximaciones al shopping: amenaza y oportunidad.

3. El tercer capítulo estudia las trasformaciones morfológicas y de usos del QSC y del sector de Iñaquito propuestos en los planes y construidos desde 1970 hasta el 2015.

4. El cuarto capítulo estudia las formas de apropiación actual del Sector de Iñaquito, donde se inserta el QSC.

5. En el quinto y último capítulo se presentarán las conclusiones de esta investigación: las tendencias del shopping center contemporáneo, la discusión de los resultados del análisis gráfico, la descripción del rol del QSC en la planificación, construcción y apropiación de Quito, y las consideraciones finales con miras a futuras investigaciones.

ACE@ AÑO 14, núm. 40, JUNIO 2019 | TRANSFORMACIONES DE LA CIUDAD Y EL SHOPPING CENTER - ANÁLISIS EN LA ESCALA 301 
Al inicio cada apartado se expondrán las herramientas y procedimientos metodológicos utilizados para su desarrollo. A continuación, realizaremos una disertación de las dos ópticas de aproximación al shopping center como base y marco teórico de este artículo.

\section{Dos aproximaciones al shopping center}

En este título, que conforma el marco teórico de esta investigación, se presentarán dos aproximaciones al shopping center: como amenaza y como oportunidad; discutidas por diferentes autores. Con base en esta disertación se podrán evidenciar diferentes discursos teóricos relacionados con el shopping center y el papel que ha desempeñado en diferentes escenarios con el paso del tiempo, desde su origen hasta la actualidad.

\subsection{El shopping center como materialización de la sociedad del consumo}

Esta primera corriente que identifica al shopping como una amenaza, se inicia desde mediados de la década de 1970 y se desarrolla hasta inicios del año 2000 en Europa y Norteamérica, y en Latinoamérica llega a finales de 2000; tendencias que coinciden en el discurso de apuntar al shopping center como uno de los principales responsables de la crisis del espacio público.

En esta corriente se presenta al shopping center como una respuesta materializada a una política neoliberal y a una sociedad de consumo (Bauman, 2000; Lipovetsky, 2007). Describe estos lugares como grandes artefactos asociados a la globalización de la cultura (globalizados y globalizantes) que homogeneizan dinámicas y manifestaciones a nivel global y "pasteurizan" las actividades que dotan de una carga simbólica o identitaria a una sociedad (Do Amaral e Silva y Assen de Oliveira, 2013), haciéndolas iguales en todo el mundo.

También se los representa como cajas cerradas genéricas (Chung et al., 2001) que pueden insertarse en cualquier sitio del planeta y siempre serán muy predecibles tanto en forma como en su funcionamiento, eliminando la posibilidad de que posean una carga identitaria propia del lugar donde está siendo emplazado (Sorkin, 2004). Se los considera "elefantes blancos", totalmente amurallados, uniformizados y estandarizados en todo el mundo (Borja, 2003) que, por su condición hermética, niegan la ciudad y aniquilan cualquier posibilidad de relación con su entorno.

Algunos autores acusan al shopping center de reemplazar al espacio público al haber colonizado actividades antes existentes y posibles únicamente en él (Sarlo 2009; 2006; 1994; Sorkin, 2004; Borja y Muxí, 2000). Se los resalta como los responsables de la segregación socio-espacial, al no ser un receptor de una gama de usuarios que incluya a quienes no tienen un poder adquisitivo suficiente para consumir y esto se manifiesta en un radio de acción mayor al de su arquitectura misma (Harvey, 2004). Esta arquitectura es catalogada como un espacio donde se engaña al usuario creando una "falsa sensación de democracia" y de inclusión social (Sarlo 2009; 2006), haciéndolo partícipe de un falso acceso a la mercadería (que es únicamente visual para muchos).

Borja (2002; 1998) presenta a los centros comerciales como una "caricatura" de un centro urbano: un parque temático donde todo está controlado y donde el primer y último fin es el de

ACE@ AÑO 14, núm. 40, JUNIO 2019 | TRANSFORMACIONES DE LA CIUDAD Y EL SHOPPING CENTER - ANÁLISIS EN LA ESCALA 302 
lucrar con el consumo de la gente, manipulando sus actividades y necesidades, recreando un paraíso de aceptación en una cultura del miedo a ser rechazados. Se trata, entonces, de una ciudad donde los promotores construyen estos grandes complejos comerciales, y compran grandes parcelas de suelo a su alrededor para poder especular con el costo de la tierra, y así poco a poco la ciudad deviene en un territorio "planificado" por agentes privados (en conjunto con el gobierno y otros promotores), configurado por la sumatoria de estos emprendimientos.

La distancia espacial ha debilitado los encuentros sociales en lugares físicos y en los espacios públicos tradicionales y, en consecuencia, ha modificado la naturaleza de "lo local". Esta noción de pérdida de un centro espacial de encuentro para las prácticas sociales incentiva la homogeneización de la sociedad en espacios globalizados como los shopping centers. En esa línea, el equipo de la publicación Harvard Project on the city argumenta que: Las galerías comerciales han reemplazado a los parques y las plazas que fueron "tradicionalmente el lugar de la libertad de expresión.... El fluido vital de la economía, que en tiempo estaba en el centro de la ciudad, se ha trasladado a los centros comerciales de la periferia, los cuales han desplazado a los distritos de negocios del centro como lugares de la actividad social y comercial... La característica predominante de su comportamiento es la capacidad de incorporarlo todo. En esas galerías comerciales se encuentran la mayoría de los usos y actividades que llevan a cabo los ciudadanos fuera de sus casas.... En su interior no sólo hay tiendas de todo tipo y tamaño, sino grandes espacios abiertos a disposición del público, útiles para múltiples usos. Hay espacios para vagar, para sentarse y para hablar". (Chung et al., 2001, p. 154)

Según Bauman (2000), el consumo se ha tornado central en la vida de las personas, el propósito de su existencia misma. Experimentar emociones relativas al querer, desear y anhelar se ha convertido en el fundamento de la economía en las ciudades y, sobre todo, de las relaciones humanas. En palabras de Baudrillard (1998), la sociedad del consumo se ha materializado en un solo espacio, "[...] este matrimonio de confort, belleza y eficiencia [...]. Estamos aquí en el corazón del consumo como organización total de la vida cotidiana, homogeneización total, donde todo se toma y se supera en la facilidad y transparencia de una «felicidad» abstracta, definida únicamente por la resolución de las tensiones. La farmacia de gran tamaño en forma de centro comercial, ciudad del futuro, es el sublimado de toda vida real, de toda vida social objetiva, en la que no sólo desaparecen el trabajo y el dinero, sino también las estaciones. [...] el trabajo, el ocio, la naturaleza y la cultura: todas estas cosas que una vez fueron dispersadas, que en otro tiempo generaron angustia y complejidad en la vida real, en nuestras ciudades anárquicas y arcaicas, todas estas actividades desgarradas, estas actividades eran más o menos irreductibles se mezclan, se climatizan y se homogeneizan en el mismo panorama de compras perpetuas. ¡Todos son ahora iguales en el mismo ambiente hermafrodita de la moda! [...]. Eso es todo ahora. [...]. Se filtra por todas partes en la indistinción de las cosas y las relaciones sociales. Así como los dioses de todos los países coexistieron sincréticamente en el Panteón Romano en un inmenso "digesto", así todos los dioses - o demonios - de consumo se han reunido en nuestro Súper Centro Comercial, que es nuestro Panteón. En otras palabras, todas las actividades, el trabajo, los conflictos y las estaciones se han unido y abolido en la misma abstracción. La sustancia de la vida unificada de esta manera, en esta digestión universal, ya no puede tener en ella ningún significado: lo que constituyó el trabajo de los sueños, el trabajo de la poesía y del significado, en otras palabras, los grandes esquemas del desplazamiento y la condensación, grandes figuras de la

ACE@ AÑO 14, núm. 40, JUNIO 2019 | TRANSFORMACIONES DE LA CIUDAD Y EL SHOPPING CENTER - ANÁLISIS EN LA ESCALA 303 
metáfora y la contradicción, que se basan en la interconexión viva de elementos distintos - ya no es posible. La sustitución eterna de elementos homogéneos reina ahora sin reto. Ya no hay ninguna función simbólica, sino simplemente una combinatoria eterna de "ambiente" en una primavera perpetua." (Baudrillard, 1998, p. 43)

Por otra parte, López-Levi (1999) describe al shopping center como un escenario de múltiples simulaciones o recreaciones de espacios públicos: una plaza, un lugar de esparcimiento, un lugar de compañía, un lugar de inclusión, una comunidad. Adicionalmente, Caprón y Sabatier (2007) sugieren que estas formas que adopta el shopping center responden a la "nostalgia" o a una idea romántica de la ciudad tradicional, clásica o idealizada. Por consiguiente, el shopping center contribuye a mantener un cierto grado de vida pública en un espacio privado y, como resultado, incentiva a la privatización de la vida urbana.

Sarlo $(2009 ; 2006 ; 1994)$ se enfoca en la fragmentación y segregación socio-espacial que incentivan estos artefactos de consumo. La investigadora argumenta que el shopping center latinoamericano ha sustituido a la ciudad, pues se ha encargado de reemplazar todas las dinámicas que ocurrían en el espacio público: en las plazas, en las calles, y las ha trasladado al interior de una caja cerrada, privatizando el espacio urbano de encuentro colectivo. Se trata, desde su punto de vista, de un espacio que ha reemplazado todas las actividades urbanas y sus espacios tradicionales de encuentro, de recreación y de intercambio.

Esto provoca transformaciones importantes en las jerarquías espaciales de las ciudades, modificando las lógicas de la planificación y del desarrollo urbano- territorial en diferentes escalas.

Así, esta aproximación crítica se estructura fundamentalmente desde el argumento que señala que el consumo ha ocupado demasiado espacio en la vida cotidiana de las personas y ha transfigurado el sentido de la existencia misma de las ciudades y de las personas que la habitan, para quienes ir al shopping center a consumir se ha convertido en el fin de todas las actividades humanas.

En resumen, esta corriente de "satanización" del shopping center, que lo considera una amenaza para la ciudad, pertenece, en su mayoría, a discursos académicos que convergen en los siguientes planteamientos: la crisis del espacio público en Norteamérica, Europa y Latinoamérica (diferentes momentos); el fortalecimiento de una sociedad individualista y globalizada (Ascher, 2004; Sennet, 2006; 2002; Harvey, 2004); la expansión de la economía neoliberal y la producción de la ciudad por agentes privados, con al alto nivel de consumo en lugares de encuentro colectivo (Bauman, 2000; Dupuy, 1998); la construcción de la ciudad como un parque temático (Sorkin, 2004) que recrea la vida pública de las plazas y las calles en un ambiente cerrado y controlado y destinado estrictamente para el consumo (Sennet, 2006); y la reconfiguración y organización del paisaje y el territorio con base en el shopping center (Chung et al., 2001).

A continuación, se expondrá algunas propuestas teóricas correspondientes a la segunda corriente de aproximación al shopping center que se presenta como una óptica contraria a la descrita en este título. 


\subsection{El shopping center como oportunidad de sociabilidad}

Esta segunda línea de pensamiento postula al shopping center como una serie de espacios que permiten el desarrollo de nuevas formas de apropiación, de sociabilidad, de oportunidad para encontrarse entre diversos usuarios y de diversidad de actividades (Napadensky y Rivera, 2015). A ella pueden adscribirse los discursos entusiastas de Victor Gruen sobre el origen del shopping center en 1964, los cuales son retomados a partir de los inicios de la década de 1990 en Europa y Norteamérica y a partir de 2000 en Latinoamérica, como una clara respuesta o solución a la crisis del espacio público.

Esta corriente discute narrativas científicas que identifican al shopping center como un fenómeno que ha provocado transformaciones en la ciudad: en su forma, en su lógica de circulación de bienes y de personas, en el reordenamiento de usos, y en el comportamiento de sus usuarios.

Varios de estos autores critican la narrativa "romántica" del espacio público inclusivo y democrático (que en realidad también fueron segregadores y generadores de control de grupos sociales), y lo analizan desde un punto de vista, a nuestro juicio, más neutral (Delgado y Malet, 2013; Crawford, 1999; De Solá Morales, 1992). Así, en tales estudiosos se despierta un mayor interés por el Shopping Center, al que se advierte como un elemento que responde eficientemente a las necesidades contemporáneas de encuentro social, de abastecimiento, de recreación y de ocio (Wall, 2005), trayendo nuevamente a discusión argumentos publicados por Víctor Gruen (1964), el arquitecto que da origen al Shopping Center.

Muchos de estos exponentes postulan que el shopping center, al igual que muchos espacios colectivos (públicos o privados), enriquece el espacio urbano a partir de las nuevas dinámicas de sociabilidad que suscitan (De Solá Morales, 1992; Secchi, 2013).

Manuel de Solá Morales, por ejemplo, en su texto "Espacio Público/Espacio Colectivo" (1992), defiende que los límites entre los espacios públicos y privados de encuentro colectivo se han venido disolviendo cada vez con mayor intensidad. Argumenta, en tal sentido, que los espacios públicos, para ser efectivamente apropiados, requieren de los comercios, de las viviendas y de los equipamientos (públicos o privados) como envolventes esenciales para garantizar la copresencia en ellos.

En paralelo a ese texto, Manuel de Solá Morales junto con Rafael Moneo diseñan y construyen el primer centro comercial de Barcelona: Illa Diagonal. Este edificio se materializa e inaugura en 1993 como la conclusión y materialización espacial de su escrito donde resaltan la importancia del espacio colectivo, en la medida en que facilita la sociabilidad, el encuentro, el entretenimiento, el acceso a servicios y al comercio, independiente de que sea público o no. El centro comercial Illa Diagonal fue presentado como una intervención de reactivación y regeneración urbanística, iniciando así, el discurso del shopping center como una nueva forma de producir ciudad de calidad.

El Illa Diagonal es un contenedor de diversos usos en diferentes escalas. Incluso ha sido descrito por sus creadores como un portador de centralidad, por el grado de diversidad y concentración e intensidad de usos, usuarios, actividades, situaciones y dinámicas que facilita. 
Asimismo, en esta tendencia teórica se describen los elementos positivos que ha tenido la construcción de estos espacios resaltando que se han convertido en contenedores de la vida pública de la ciudadanía, han configurado nuevas identidades y sus usuarios le han otorgado un valor simbólico de espacio de encuentro y sociabilidad.

En el contexto latinoamericano, la bibliografía respectiva es más reducida, sin embargo, algunos autores analizan al shopping center como nuevos gérmenes de centralidad urbana que aglomeran mucha más diversidad de usos y usuarios que muchos de los espacios públicos de las ciudades (Paquette, 2007; Cáceres, Sabatini, Salcedo y Blonda, 2006).

Los usuarios de los shopping centers no solamente buscan satisfacer su necesidad de compra, sino también entrar en co-presencia y generar encuentros, ser parte de un colectivo, sin perder su condición de individuo. El anonimato que se puede experimentar en el shopping center es una de las condiciones positivas que rescatan Sandikci y Holt (1998). Destacan que es interesante observar a la gente ir solamente a vitrinear y a mantener un mínimo de contacto entre usuarios y con los vendedores; sentirse acompañados sin sentirse invadidos.

En investigaciones realizadas por Stillerman y Salcedo (2010) los autores concluyen que los shopping centers son espacios diversos donde es posible construir identidades según el grupo etario, étnico, social o económico. Niegan que el shopping center sea un lugar que aniquila lo cotidiano puesto que la gente asimila los espacios y transponen prácticas de otros espacios de encuentro colectivo; se apropian, lo habitan y se refieren a él de una manera muy familiar.

Los consumidores entienden al shopping center como un espacio de interacción que se ha convertido en una extensión de la casa (Salcedo, 2003), adecuando al espacio del cual se apropian para incorporarle una carga simbólica al espacio con una atmósfera propia. Se puede ver a parejas cortejando o a familias celebrando cumpleaños de los niños o adultos; actividades que afirman la cotidianidad de la vida de los usuarios y contradicen la idea de que el shopping center constituye una amenaza. Efectivamente, los niños, adolescentes y padres jóvenes visitan el shopping center para socializar, para jugar, para esparcirse, sin sentirse -por ciertovulnerables o alertas al peligro, lo cual facilita la sociabilidad, sobre todo entre los grupos de niños que se recrean en los espacios diseñados para ellos mientras sus padres conversan o comen

Los jóvenes se apropian de los espacios colectivos del shopping center y los transforman en territorios con una carga simbólica para manifestarse y construir identidades (Urteaga y Cornejo, 1995). En ellos expresan su cultura sin miedo a ser atacados por otros grupos que representen un ideal o una cultura distinta u opuesta.

En varios espacios del shopping center, los grupos de jóvenes se sienten escuchados por actores similares a ellos y protegidos y, sobre todo, se sienten importantes como individuos más allá de su importancia como grupo ya que, al igual que los niños, pueden disfrutar un cierto grado de autonomía y anonimato que los libera de la vulnerabilidad al que están expuestos en la ciudad. Esto ha provocado que se manifiesten (incluso en relación a temas culturales locales o políticos) dentro del territorio del shopping center, se apropien de él como si fuera una extensión de sus casas, configuren discursos e identidades (Figuras 1 y 2) que reafirman su pertenencia a la ciudad. 
Figura 1. "Suicidio colectivo" por el alza del precio en aranceles universitarios - Mall Plaza El Trébol, Concepción, Chile

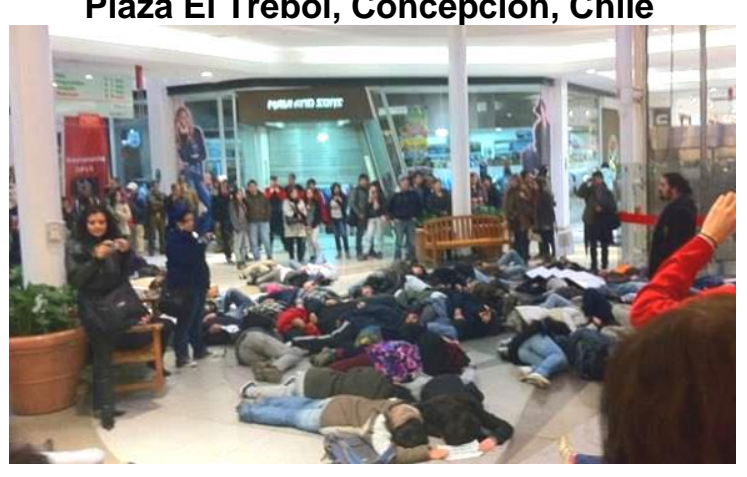

Fuente: http://media.biobiochile.cl/wpcontent/uploads/2011/06/eduardo-barria-en-twitter.jpg
Figura 2. Discusión sobre literatura y género - Quicentro Shopping Center, Quito

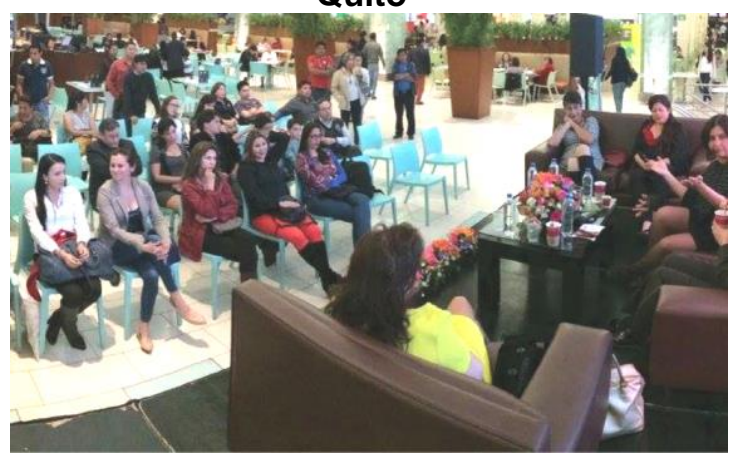

Fuente: Autor, 2015

En el ámbito latinoamericano, hay que mencionar que en la ciudad de Bogotá ya se consideró en los años 70, desde la planificación de promotores privados- al shopping center como un elemento de desarrollo urbanístico. La propuesta se llamó Ciudadela Comercial Unicentro y fue un proyecto integrado de desarrollo urbano que se inauguró en 1976. Constó de vivienda, comercio, recreación, trabajo y servicios con un shopping center como corazón. La iniciativa incentivó la construcción de nuevos barrios por el éxito que tuvo desde su construcción: Mucha gente se acostumbró a ir a Unicentro para pasear. "El término "quincear", que se aplica a quienes salen a pasear por la carrera 15, fue desbancado por el de "unicentrear". Varias sucursales de pizzerías, tabernas, restaurantes y fuentes de soda se convirtieron en lugares obligatorios de la ciudad. Ir a comerse un helado, una hamburguesa o tomarse una cerveza era sinónimo de ir a Unicentro [...]. Con el paso de los años, contrariando las suposiciones de muchos, Unicentro siguió siendo un lugar obligado de reuniones. No se trataba de una moda pasajera. Simplemente dejó de ser una novedad para convertirse en una necesidad cotidiana de cientos de miles de bogotanos. Porque además de compras y diversiones, Unicentro ofrece toda una gama de servicios complementarios como bancos, corporaciones de ahorro y vivienda, oficinas de correos, agencias de viajes, etc. Fuera de eso, en los alrededores de Unicentro se han instalado aquellas empresas de servicios que no tienen su local dentro de Unicentro, aprovechando el imán de la ciudadela. Hoy en día, ocho años después de su inauguración, Unicentro sigue siendo el centro comercial por excelencia de Bogotá y del país. Los nuevos centros que fueron construidos después, en teoría mejor ubicados, no han podido superar las especificaciones de diseño y la gama de servicios tan amplia que caracterizan a Unicentro." (Revista Semana, 1984, s/p)

Los autores que están alineados con esta línea de pensamiento sobre el shopping consideran un error juzgarlo como un símbolo de la privatización de los espacios de encuentro colectivo, como una "victoria" del sistema económico neoliberal o como un objeto genérico homogeneizado en todo el mundo, independiente de la cultura en donde es insertado. Resaltan, desde esa perspectiva, que este objeto debe ser estudiado y analizado con prolijidad y profundidad (Salcedo, 2003). El shopping center ha dejado de ser un espacio exclusivo para el consumo, al contrario, la tendencia indica que los promotores han reducido áreas de GLA (áreas para la venta) por espacios de entretenimiento, ocio y encuentro colectivo. 
Además, esta lógica del shopping center como espacio de sociabilidad lo posiciona como un germen de desarrollo y reactivación urbana, capaz de generar fuertes tensiones en las ciudades y de ocasionar transformaciones en la estructura espacial de las ellas (Stillerman y Salcedo, 2010; Cáceres, 2006; Sabatini, 2006; Salcedo, 2003). Se argumenta, por último, que estas semillas de centralidad urbana aglomeran una mayor diversidad de usos y usuarios que muchos de los espacios públicos de las ciudades y se adaptan a su entorno, incentivando a un mayor diálogo e interrelación entre estos elementos y la ciudad.

En resumen, esta corriente que representa lo opuesto a la primera aquí revisada, asume al shopping center como una serie de espacios que permiten y promueven el desarrollo de nuevas formas de apropiación, de sociabilidad, nuevas oportunidades para el encuentro de diversos usuarios y de diversidad de actividades. Además, defiende que el shopping center ha dejado de lado la tipología de caja cerrada y que persigue, cada vez más, la relación con su entorno.

La bibliografía asociada a esta tendencia teórica coincide en algunos aspectos con los discursos entusiastas de Gruen (1956), aunque dichos estudios se abocan a shopping centers localizados en zonas urbanas o pericentrales, y no en las periferias residenciales como lo hicieron a los primeros malls en Norteamérica. En suma, desde esta aproximación se exponen los elementos positivos que ha tenido la construcción de estos espacios, concluyendo que el shopping center puede ser un elemento permeable que se articula con la ciudad.

Seguidamente, se despliega el análisis gráfico del caso de estudio de esta investigación, el del sector Iñaquito y el Quicentro Shopping Center, en la ciudad de Quito, para discutir estas dos aproximaciones al shopping center y responder las preguntas de esta investigación.

\section{Concepción y construcción del centro financiero de la capital del Ecuador: Iñaquito y el Quicentro Shopping Center}

El Quicentro Shopping está localizado en el centro-norte de la ciudad de Quito, en el sector de Iñaquito, actual centro financiero de la capital del Ecuador (Figura 3), en un terreno que, originalmente, fue una hacienda de pastoreo y ganado de 25,5 hectáreas.

Figura 3. Localización del Quicentro Shopping Center en Quito, Ecuador

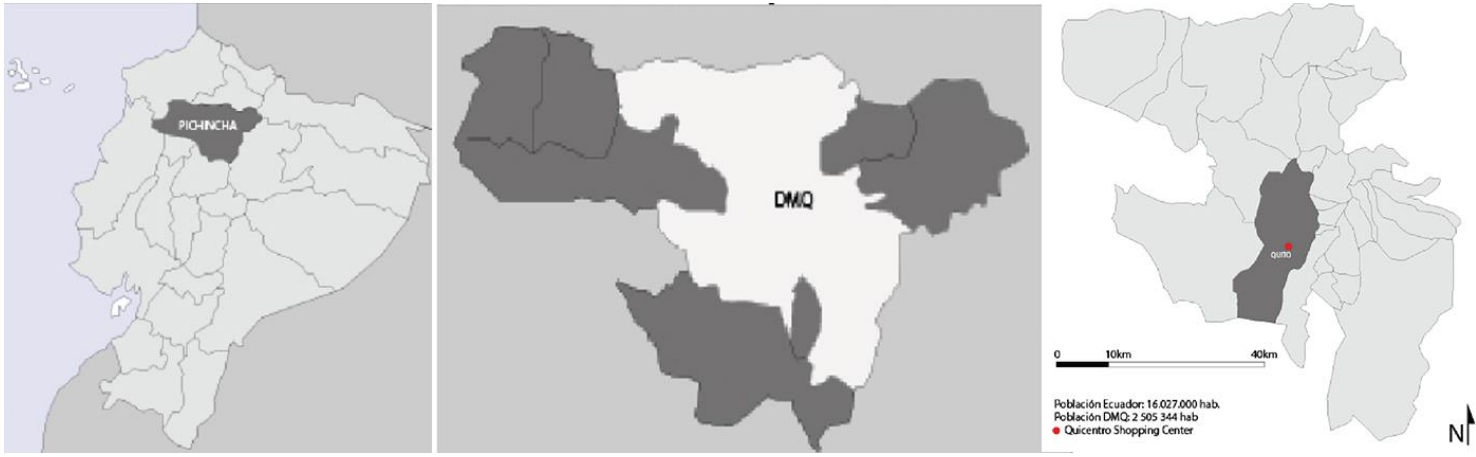

Fuente: Elaboración propia a partir de mapas del Instituto Geográfico Militar del Ecuador.

ACEO AÑO 14, núm. 40, JUNIO 2019 | TRANSFORMACIONES DE LA CIUDAD Y EL SHOPPING CENTER - ANÁLISIS EN LA ESCALA 308 DEL SECTOR DE IÑAQUITO Y EL QUICENTRO SHOPPING CENTER EN QUITO 
En década de los años 70 , se destina el terreno de la hacienda para la construcción de un proyecto de vivienda multifamiliar (que constaba en el plan de 1967 como estrategia para desarrollar la zona y descentralizar la ciudad). Por ordenanza municipal de la época (Municipio de Quito, 1967), el 15\% del terreno debía ser cedido al municipio de Quito como espacio público para la construcción de áreas verdes (Figura 4).

Figura 4. Lote original donde se inserta el QSC en los años 60 (izq.) y el lote actual (der.)

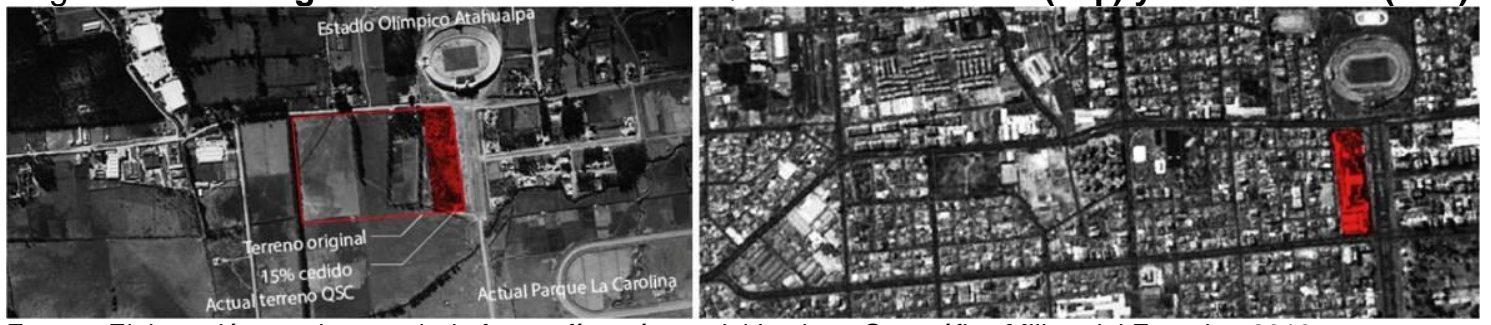

Fuente: Elaboración propia a partir de fotografías aéreas del Instituto Geográfico Militar del Ecuador, 2016.

En 1977, el 15\% del terreno cedido por el proyecto de vivienda, con un área total de 3,6 hectáreas fue rematado por el Municipio de Quito para obtener recursos destinados a realizar obras en épocas de crisis y, finalmente, fue vendido a Alberto Deller, quien sería posteriormente presidente de la compañía promotora y constructora del Quicentro Shopping Center. El sector de Iñaquito, concebido como un centro financiero desde el primer plan ordenador (1942), se constituyó, desde los años 80, en el sector con mayor grado de centralidad de la ciudad. La zona se ha venido transformando, durante estas décadas, a nivel de trazado, de parcelamiento, de edificación y de usos y ha fortalecido su rol de centralidad en la ciudad de Quito. En las Figuras 5 y 6 se puede comparar el sector de Iñaquito en los años de 1960 y en el año 2014. Es evidente aquí la transformación en los niveles de ocupación del sector y de su entorno.

Figura 5. Sector de Iñaquito, 1960

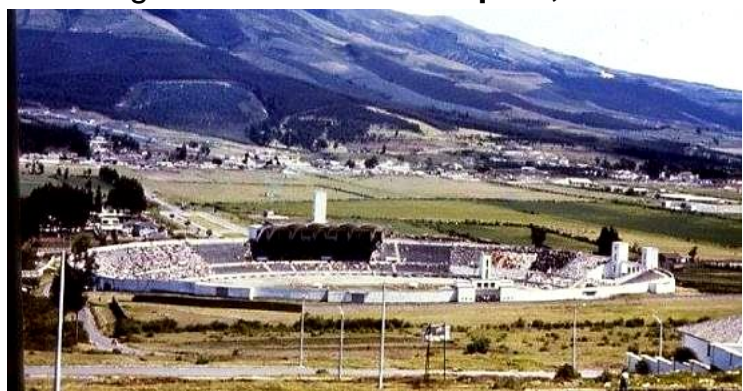

Fuente: http://img205.imageshack.us/img205/7298/ 42627210150663421188905.jpg
Figura 6. Sector de Iñaquito, 2014

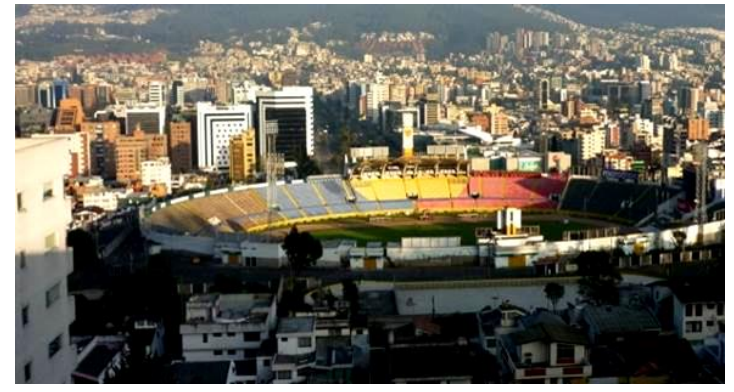

Fuente: Autor, 2014

Actualmente, el Quicentro Shopping Center está involucrado en algunos proyectos urbanísticos de planificación municipal en su entorno inmediato, ya sea a través de alianzas públicoprivadas o simplemente por las relaciones que se producen por su proximidad con el Quicentro. Dentro de estos proyectos urbanísticos en la escala de ciudad y sector, planteados por el Gobierno Nacional y por el Municipio de la ciudad de Quito, sobresalen tres:

1. La construcción del Bulevar Naciones Unidas en el año 2010, que limita la fachada sur del Quicentro, para lo cual fue convenido con el Municipio de Quito eliminar algunas franjas de estacionamientos en planta baja con el fin de ampliar las veredas. (A partir de estas

ACE@ AÑO 14, núm. 40, JUNIO 2019 | TRANSFORMACIONES DE LA CIUDAD Y EL SHOPPING CENTER - ANÁLISIS EN LA ESCALA 309 DEL SECTOR DE IÑAQUITO Y EL QUICENTRO SHOPPING CENTER EN QUITO 
modificaciones se ha expandido, por cierto, el espacio público del Shopping Center, pues incorpora actividades del Boulevard NNUU dentro del Quicentro). Se trata de una alianza público-privada.

2. La construcción del Metro de Quito (ya construida en un $80 \%$ y proyectada su finalización para el año de 2019), y la localización de dos las paradas a menos de 500 metros del Quicentro.

3. Tras un concurso público nacional en 2012, se anunció la construcción de dos plataformas gubernamentales en el sector de Iñaquito: Plataforma Financiera y Plataforma de Producción, donde se concentrarán poderes y servicios de las diferentes áreas vinculadas a la producción e intercambio (nacional e internacional) de productos. La Plataforma Financiera está en funcionamiento desde inicios de 2017 a una distancia de 400 metros del Quicentro.

Con estos proyectos ya se puede percibir la estrecha relación que existe entre la construcción de la ciudad y el Quicentro Shopping Center. Después de presentar al sector de Iñaquito y al Quicentro Shopping Center en el contexto de su planificación y construcción, se expondrá el análisis gráfico del efectivo uso de suelo, la densidad, el transporte y la estructura espacial, buscando visibilizar las efectivas repercusiones de este shopping center en el actual centro financiero de Quito.

Para llevar a cabo la labor, se levantó, con GIS, 5 planes especiales para Iñaquito y el diagnóstico realizado previamente a la elaboración de los planes, procurando evidenciar la dialéctica en escala intermedia (Rossi, 2007; De Solá Morales, 1992) del sector y del Quicentro Shopping Center, concebidos y construidos.

Las variables cuantitativas levantadas para ambos componentes espaciales fueron:

- Uso de Suelo

- Densidad

- Transporte

- Edificabilidad / Zonificación

Estas cuatro variables fueron consideradas fundamentales puesto que contribuyen a medir y cuantificar, de manera gráfica, el grado de centralidad (Rossi, 2007; Ellin, 2006; Panerai, 2006; Hassenpflug, 2007; Vidal y Pol, 2005; Brandão, 2002; Santos y Voguel, 1985) de piezas urbanas a partir de su forma. Así, estas variables funcionan como indicadores de concentración, intensidad y diversidad de usos, usuarios y horarios desde la planificación y en la construcción del sector de Iñaquito.

Las cartografías resultantes de estos levantamientos fueron cruzadas con el levantamiento de la inserción de los shopping centers del sector. Desde luego, se destaca la figura del QSC en la narrativa del estudio, para examinar su repercusión en el desarrollo urbano y social. Como fue presentado en el primer capítulo de esta tesis, la subhipótesis planteada para este capítulo fue la siguiente. Existe una estrecha relación entre la planificación, la construcción y la vivencia del QSC, y las transformaciones morfológicas y el reordenamiento de usos en el sector donde se inserta. Este modelo es redundante en la planificación y en la construcción de sectores donde se busca un mayor grado de centralidad. 


\subsection{Forma y centralidad de Iñaquito con el Quicentro Shopping Center: la escala intermedia de la planificación y su materialización}

En este capítulo se presenta el análisis gráfico de la planificación y construcción del sector Iñaquito y el QSC, entre 1970 y 2015, cuya finalidad es patentizar la relación entre la inserción del shopping center y la repercusión en la reactivación, consolidación del actual centro financiero de Quito. Dicho análisis se ha efectuado desde las cuatro variables cuantitativas previamente señaladas: uso de suelo, transporte y densidad, edificabilidad / zonificación.

\section{Uso de suelo}

Las Figuras 7 a 11 muestran el uso de suelo planteado por los planes especiales del sector de Iñaquito, entre 1970 y 2015. Inicialmente, el sector fue proyectado como un centro residencial (Figura 7). Con el paso de los años, hasta alrededor del año 2000, se lo concibió como un nuevo centro de comercio y servicios, y se propuso, desde esa perspectiva, el uso de suelo multifamiliar múltiple (Figuras 7-10) que permitía albergar comercio de pequeña escala. Finalmente, en 2015 (Figura 11) se impulsó allí el uso de suelo múltiple. Es cardinal destacar la inserción de tres shopping centers en el sector desde 1970 hasta 1990, y la importante transformación del uso de suelo planificado en este período.

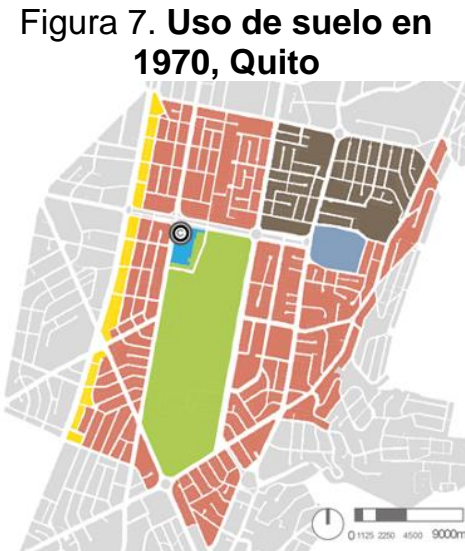

Fuente: Elaboración propia a partir del Plan Quito, 1980

Figura 10. Uso de suelo en 2000, Quito

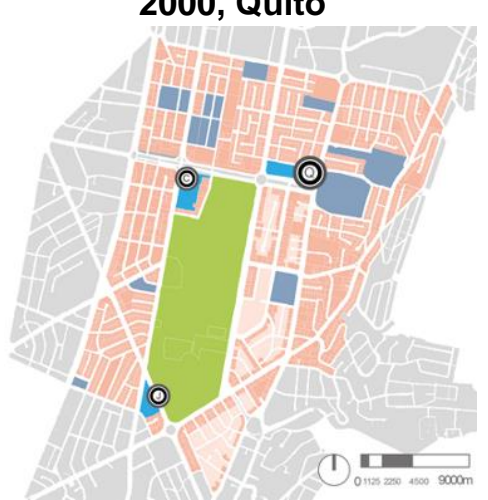

Fuente: Elaboración propia a partir del Plan Metropolitano de Ordenam. Territorial 2012-2022, 2012.
Figura 8. Uso de suelo en 1980, Quito

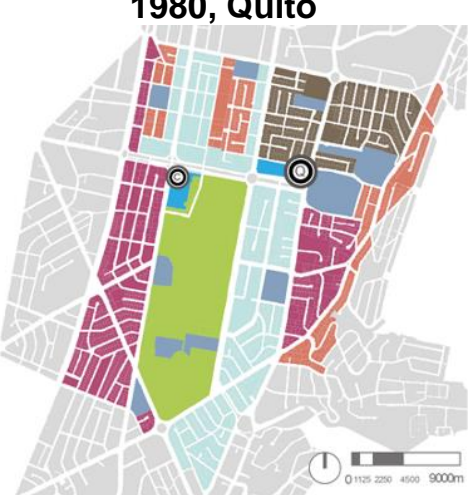

Fuente: Elaboración propia a partir del Plan Estructura Urbana, 1990.

Figura 11. Uso de suelo 2015, Quito

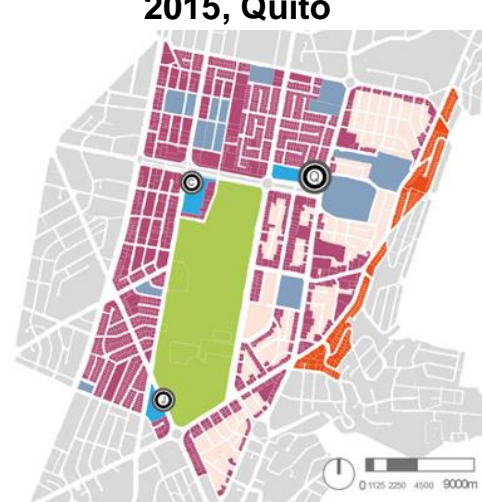

Fuente: Elaboración propia a partir del Plan de Desarrollo y Ordenamiento Territorial, 2015.

\section{Figura 9. Uso de suelo en 1990, Quito}

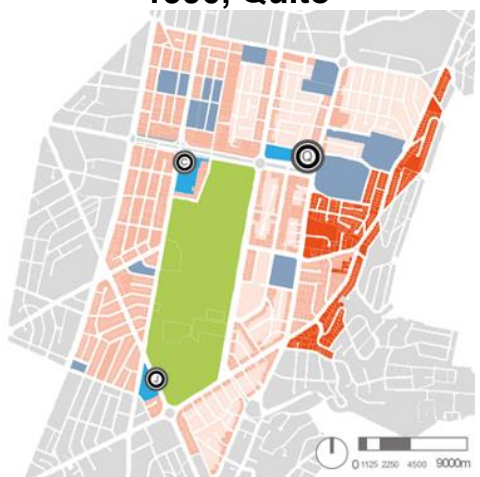

Fuente: Elaboración propia a partir del Plan General de Desarrollo Territorial 2000 - 2020, 2001.

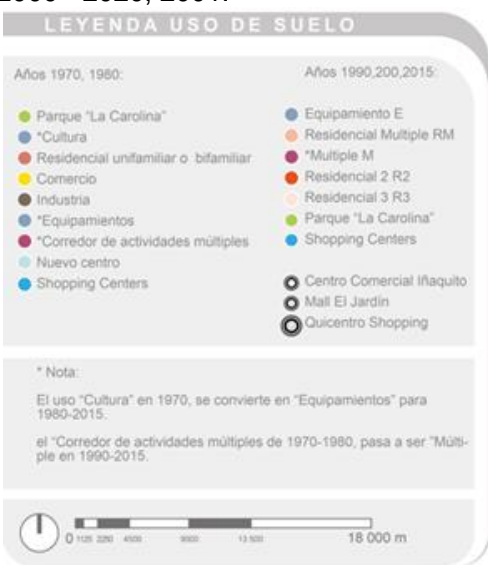

ACEO AÑO 14, núm. 40, JUNIO 2019 | TRANSFORMACIONES DE LA CIUDAD Y EL SHOPPING CENTER - ANÁLISIS EN LA ESCALA 
Las Figuras 12 a 16 grafican las efectivas transformaciones del uso de suelo en el sector de Iñaquito desde 1970 hasta 2015. Así, se verifica que, con el paso del tiempo, el uso de suelo residencial se transforma en uso de suelo múltiple, el cual continúa incrementándose, al igual que el número de equipamientos. Hay que considerar, ahora bien, que el uso de suelo residencial múltiple apareció antes del plan de 1990 y después de la construcción del QSC (Municipio de Quito, 1990) y que en el año 2015 el uso de suelo múltiple no alcanzaba el grado de concentración proyectado en el plan. Con todo, se constata un patrón de incremento del uso de suelo múltiple residencial en torno a los shopping centers.

\section{Figura 12. Uso de suelo en 1970, Quito}

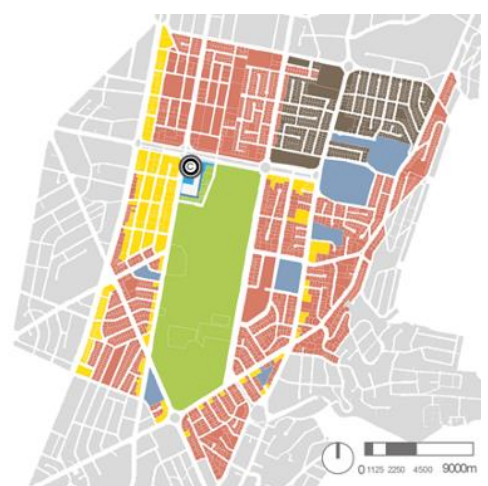

Fuente: Elaboración propia a partir del Plan Quito, 1980.

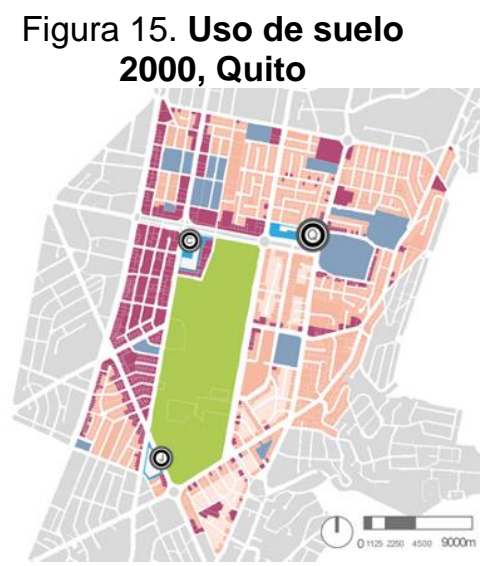

Fuente: Elaboración propia a partir del Plan Metropolitano de Ordenamiento Territorial 2012 2022, 2012.

\section{Figura 13. Uso de suelo en 1980, Quito}

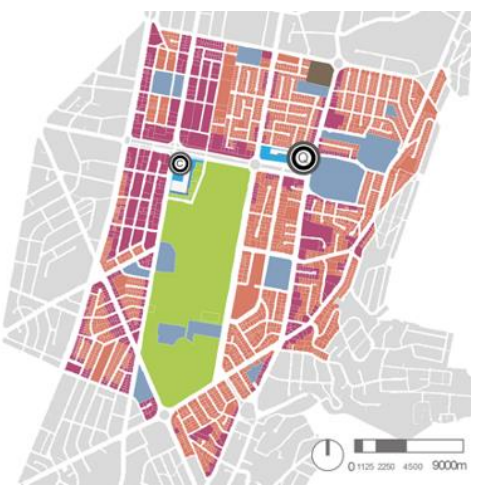

Fuente: Elaboración propia a partir del Plan de Estructura Urbana de Quito, 1990.

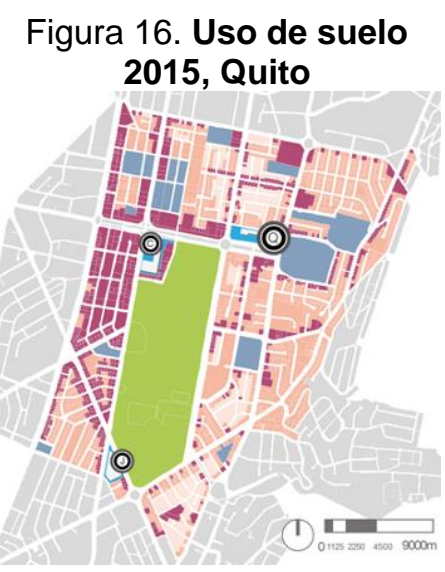

Fuente: Elaboración propia a partir del Plan de Desarrollo y de Ordenamiento Territorial, 2015.

\section{Figura 14. Uso de suelo en 1990, Quito}

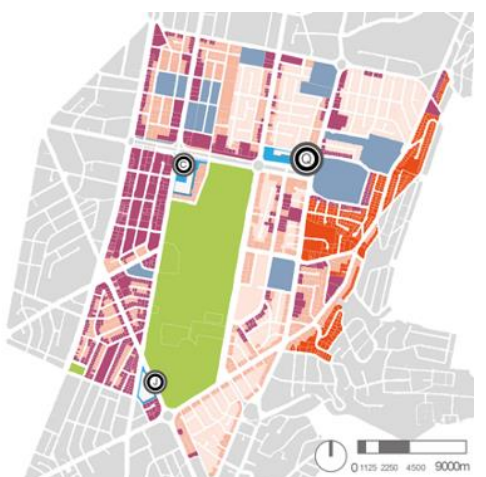

Fuente: Elaboración propia a partir del Plan General de Desarrollo Territorial 2000 - 2020, 2001.

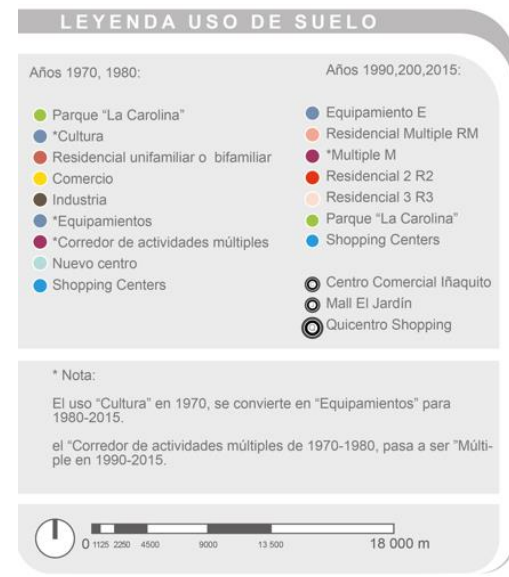

Nótese que, a medida que el tiempo avanza, se postula en los planes un incremento en el uso de suelo múltiple y de equipamientos en el sector. En los años 70 (Figura 7), se propuso que el terreno del Quicentro Shopping Center y su entorno norte fuera un área industrial de bajo impacto, sin embargo, se consolidó como un área residencial de baja densidad en la misma década. Durante los mismos años, el efectivo uso de suelo predominante es el residencial unifamiliar y bifamiliar, con unos pocos lotes de uso de suelo múltiple (Figura 7).

ACE@ AÑO 14, núm. 40, JUNIO 2019 | TRANSFORMACIONES DE LA CIUDAD Y EL SHOPPING CENTER - ANÁLISIS EN LA ESCALA 301 DEL SECTOR DE IÑAQUITO Y EL QUICENTRO SHOPPING CENTER EN QUITO 
Hacia el norte del actual QSC el uso de suelo era industrial de mediano impacto ambiental y urbano; se concentraban allí fábricas de producción ladrillos para la construcción (Municipio de Quito, 1970).

Ya para 1980 se propone que el actual terreno del QSC (donado al Municipio de Quito por normativa) fuera un equipamiento comercial, que se materializará en el Quicentro Shopping Center, en 1986. También se planificó el sector como un nuevo centro con áreas residenciales y uso de suelo comercial y de servicios (Figura 8) que se consolidó como un área residencial con corredores comerciales, donde se incrementa el uso de suelo múltiple y se reduce el uso de suelo industrial. Únicamente se mantiene una fábrica de ladrillos en uno de los lotes del sector, el cual posteriormente, en la década de los 90 (Figura 9), es planificado como un equipamiento gubernamental, el Ministerio del Deporte, con infraestructura para realizar algunas prácticas deportivas abiertas a la ciudadanía.

Así también se eleva el número de equipamientos construidos en el sector y el área residencial propuesta en el plan de 1980 se transforma en residencial múltiple (MUNICIPIO DE QUITO, 1990) (Figura 14), que permitiría el uso residencial y diversos usos en escala zonal (que posibilita el uso de suelo residencial con uso comercios y servicios de escala sectorial y de ciudad).

En este mismo período, algunas zonas proyectadas como residenciales transformaron, de igual forma, su uso de suelo en residencial 3 R3 (que permite el uso de suelo residencial acompañado de comercio, servicios y equipamientos de escala barrial, sectorial y zonal), en residencial 2 R2 (que permite el uso de suelo residencial con uso comercios y servicios de escala barrial y sectorial) y en equipamientos en escala barrial, sectorial y zonal.

Desde el año 2000 se impulsa en el plan el uso de suelo residencial múltiple que permite el comercio en escala barrial, y en el año 2015 se posibilita el uso de suelo múltiple en casi todo el sector, aumentando con ello su grado de centralidad (Figuras 10 y 11). Con relación al efectivo uso de suelo del sector, entre el año 2000 y 2015 (Figuras 15 y 16), baste anotar que se intensifica el uso de suelo múltiple, múltiple residencial y el uso de suelo residencial 3 R3. El uso de suelo múltiple o residencial múltiple se concentra en todo el sector, incluyendo el entorno inmediato de los shopping centers.

En definitiva, estas cartografías reflejan que la diversidad de usos en el sector de Iñaquito planificado y construido no ha disminuido a partir de la inserción de los shopping centers, aun cuando el uso de suelo múltiple no alcanza la proyección del plan. Es interesante, de todas maneras, que, a pesar de tratarse un centro financiero, la zona ha mantenido en su construcción su carácter residencial; condición que permite que exista una mayor diversidad de actividades, horarios en los que estas se desarrollan y usuarios. Ello igualmente libera al sector de un destino únicamente laboral.

Se demuestra con este análisis que el QSC es parte de un complejo y diverso centro residencial, financiero, comercial y de servicios que, contrariamente a aquella visión que concibe el shopping center como una amenaza para la ciudad, ha sido un componente esencial en la construcción de dicha centralidad. 


\section{Transporte}

En las Figuras 17-21 se puede observar las propuestas de articulación del sector con diferentes medios de transporte público masivo en diferentes años. En 1970 (Figura 17) el sector tenía planificado únicamente una línea de bus y una parada. En la década siguiente (Figura 18) se planteó otra línea de bus que articulaba el sector en sentido este-oeste con tres paradas (dos de ellas coincidían con el $\mathrm{CCl}$ y el Quicentro Shopping). Entonces es además construido el Quicentro Shopping Center, el cual ya se inserta en un terreno con transporte proyectado. A partir de los años noventa (Figuras 19-21), desde la planificación, se busca dotar a este sector con diferentes medios de transporte que abastezcan el ingreso, la salida y el movimiento interno: BRT's, metro, ciclovías y nuevas líneas de bus, que aumentan el grado de centralidad del sector.

Figura 17. Transporte en 1970, Quito

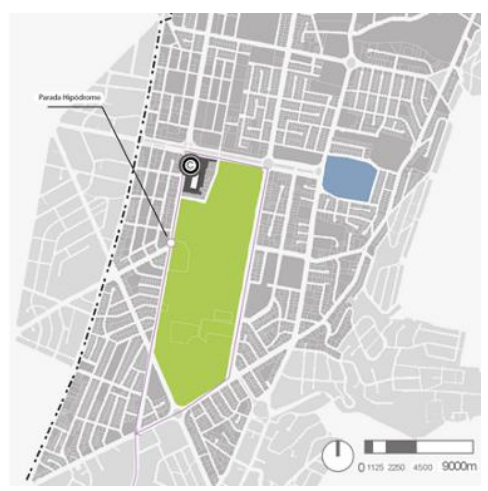

Fuente: Elaboración propia a partir del Plan Quito, 1980.

Figura 20. Transporte en 2000, Quito

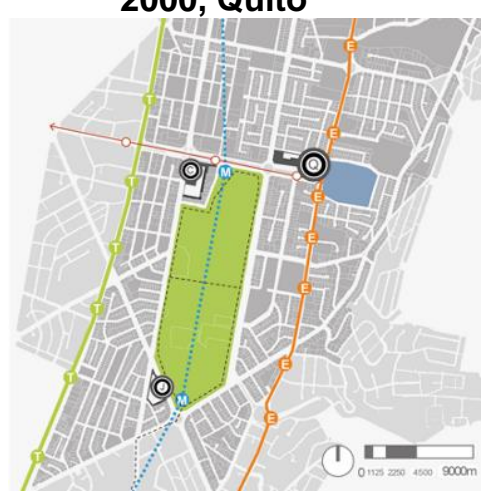

Fuente: Elaboración propia a partir del Plan Metropolitano de Ordenamiento Territorial 2012 2022, 2012.
Figura 18. Transporte en 1980, Quito

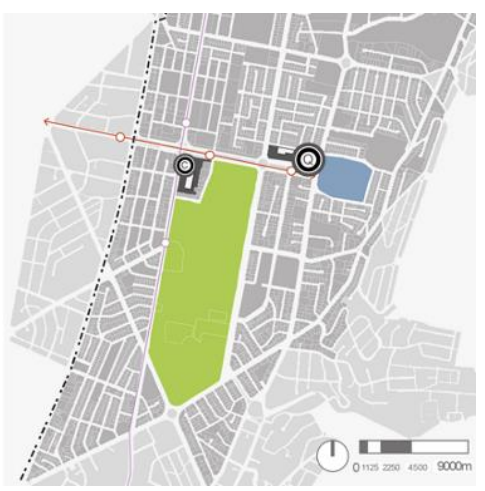

Fuente: Elaboración propia a partir del Plan de Estructura Urbana de Quito, 1990.

\section{Figura 21. Transporte en} 2015, Quito

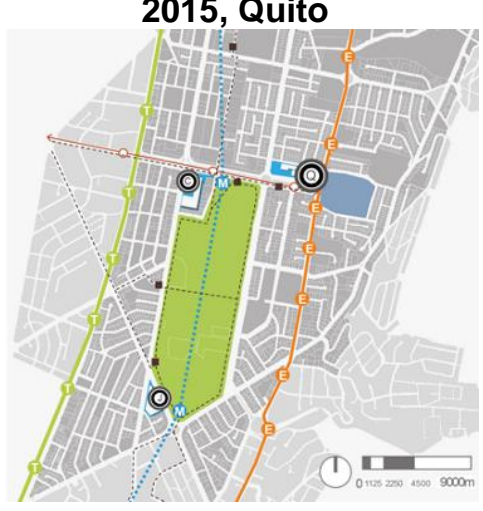

Fuente: Elaboración propia a partir del Plan de Desarrollo y de Ordenamiento Territorial, 2015.
Figura 19. Transporte en 1990, Quito

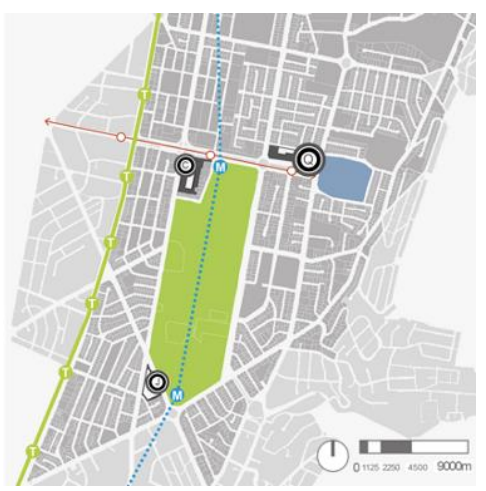

Fuente: Elaboración propia a partir del Plan General de Desarrollo Territorial 2000 - 2020, 2001.

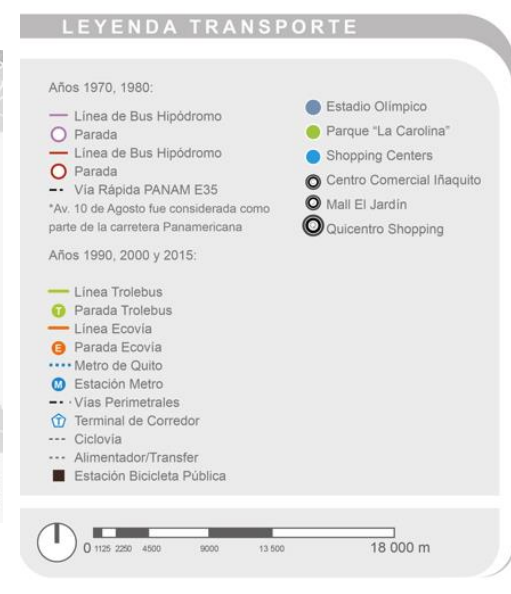

En las Figuras 22-26 se visibiliza la efectiva articulación del sector con diferentes medios de transporte público. En los años 70 , según ilustra la Figura 22, el transporte del sector coincide con lo que se planificó en el mismo período y contaba únicamente con una línea de bus

ACEO AÑO 14, núm. 40, JUNIO 2019 | TRANSFORMACIONES DE LA CIUDAD Y EL SHOPPING CENTER - ANÁLISIS EN LA ESCALA 303 DEL SECTOR DE IÑAQUITO Y EL QUICENTRO SHOPPING CENTER EN QUITO 
"hipódromo" (haciendo referencia al hipódromo construido en el Parque La Carolina) y una parada próxima al CCl.

\section{Figura 22. Transporte en 1970, Quito}

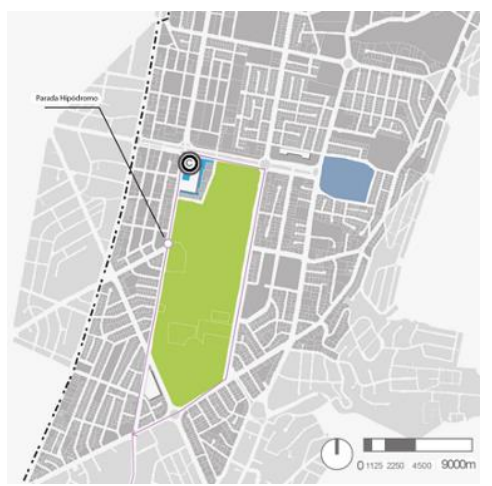

Fuente: Elaboración propia a partir del Plan Quito, 1980.

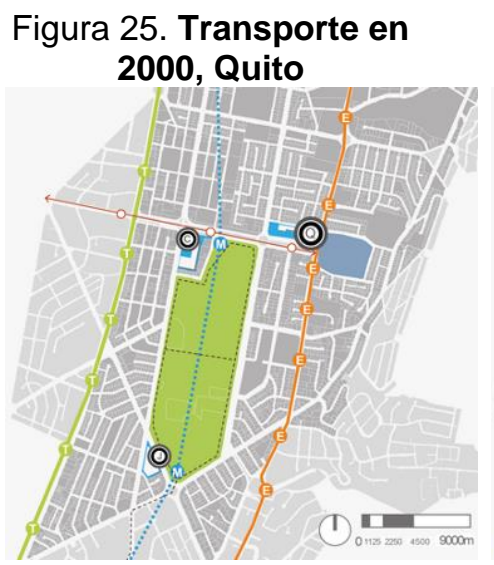

Fuente: Elaboración propia a partir del Plan Metropolitano de Ordenamiento Territorial 2012 2022, 2012.
Figura 23. Transporte en 1980, Quito

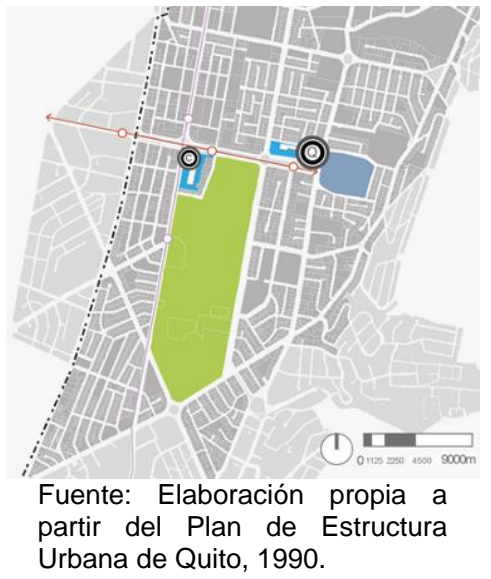

Figura 26. Transporte en
2015, Quito

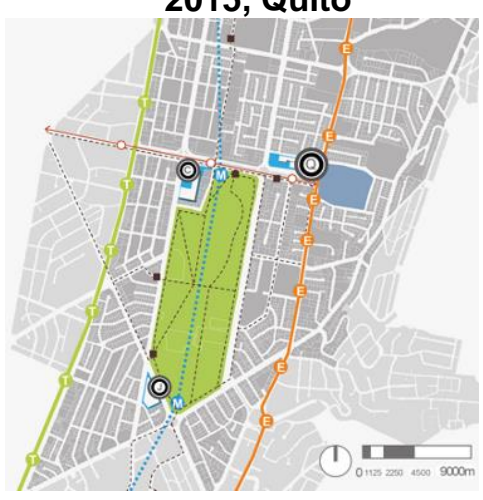

Fuente: Elaboración propia a partir del Plan de Desarrollo y de Ordenamiento Territorial, 2015.
Figura 24. Transporte en 1990, Quito

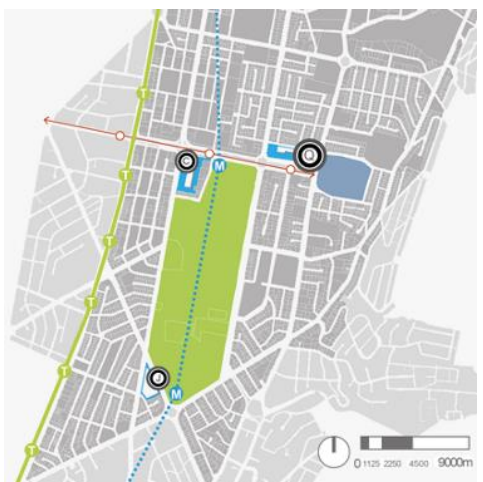

Fuente: Elaboración propia a partir del Plan General de Desarrollo Territorial $2000-2020,2001$.

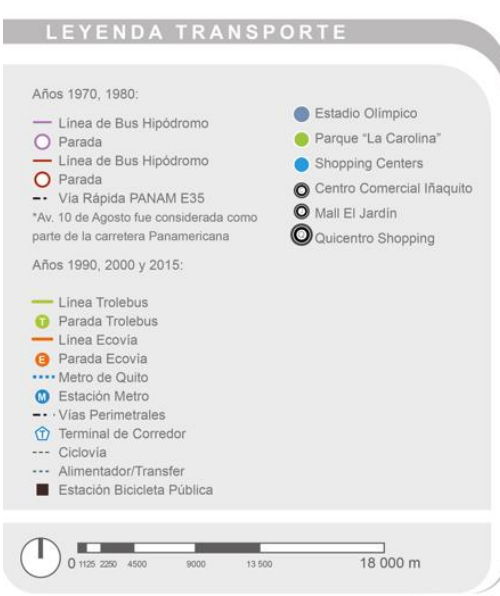

A partir de 1990 (Figuras 27-31), el sector es abastecido con diferentes medios de transporte que facilitaron el ingreso, la salida y el movimiento interno del sector: BRT's, metro, ciclovías y nuevas líneas de bus, que fueron incrementando el grado de centralidad del sector. Debe destacarse aquí la efectiva articulación de todos los medios de transporte con los shopping centers de Iñaquito.

Como en los apartados previos, las cartografías elaboradas revelan el incremento de accesibilidad con transporte público (y privado) al sector de Iñaquito, planificado y construido, donde fueron igualmente planificados y construidos tres de los ocho shopping centers suprarregionales de Quito. 
Resalta, en este contexto, la concentración de transporte público que abastece este centro financiero de Quito donde se inserta el QSC, lo cual refleja un alto grado de accesibilidad para usuarios que se desplazan desde cualquier lugar de la ciudad y de cualquier nivel de renta; situación que incentiva, a su vez, una apropiación del sector por parte de diferentes grupos sociales.

\section{Densidad}

En cuanto a la densidad poblacional planificada, se puede apreciar en las Figuras 27-31 que, desde el plan de los años 70 hasta el del 2015, se ha venido concretando un incremento de densidad en el sector de $18-60$ habitantes por hectárea a $180-270$. Las Figuras sugieren, por lo demás, un crecimiento de población de hasta diez veces más en el sector en cuestión. Es importante advertir que también se impulsa una modificación del microparcelamiento (lotes) en lotes de mayor tamaño para áreas destinadas a la construcción de equipamientos.

\section{Figura 27. Densidad de población 1970, Quito}
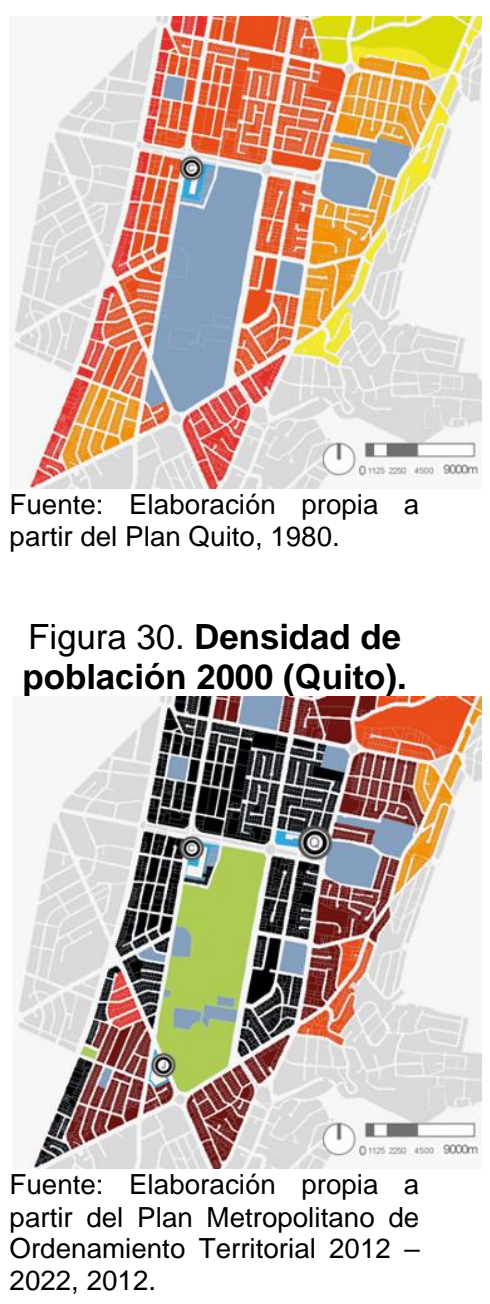

Figura 28. Densidad de población 1980, Quito

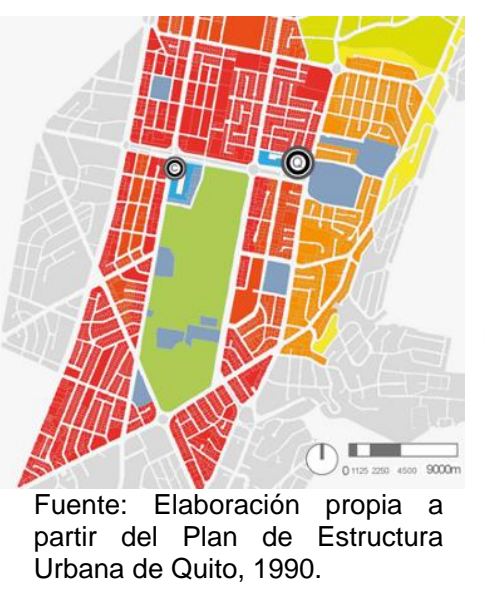

Figura 31. Densidad de

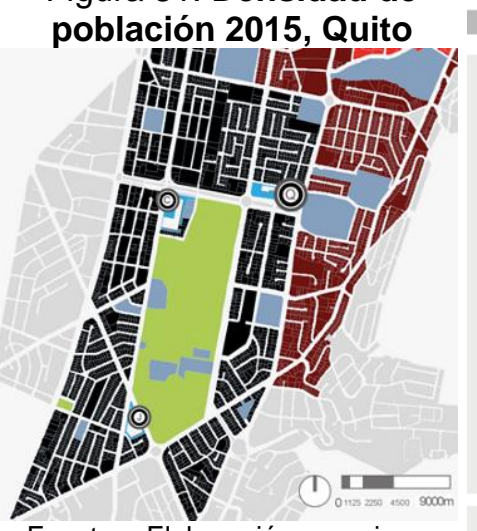

Fuente: Elaboración propia a partir del Plan de Desarrollo y de Ordenamiento Territorial, 2015.
Figura 29. Densidad de población 1990, Quito

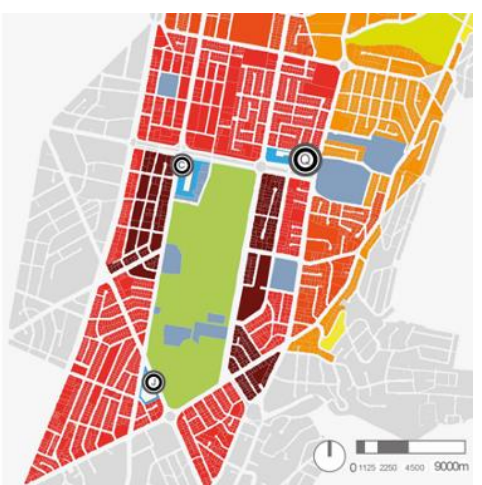

Fuente: Elaboración propia a partir del Plan General de Desarrollo Territorial 2000 - 2020, 2001.

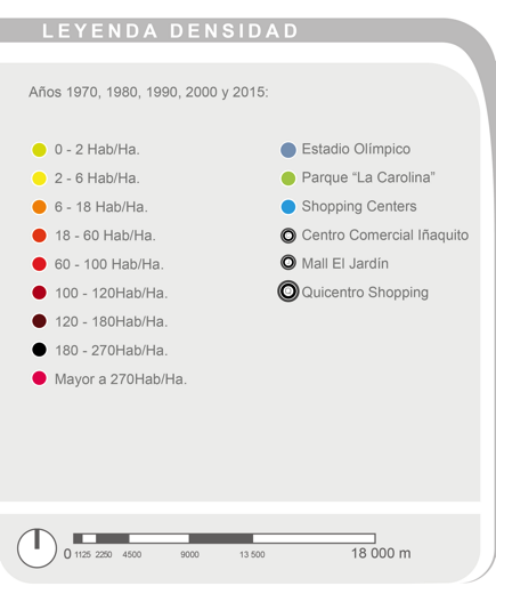

ACEO AÑo 14, núm. 40, JUNIO 2019 | TRANSFORMACIONES DE LA CIUDAD Y EL SHOPPING CENTER - ANÁLISIS EN LA ESCALA 302 DEL SECTOR DE IÑAQUITO Y EL QUICENTRO SHOPPING CENTER EN QUITO 
Respecto a la efectiva densidad poblacional desde 1970 hasta 2015, se puede constatar a través de las Figuras 32-36 que esta aumentó en todo el sector, incluso a mayor velocidad y en mayor cantidad que la concebida en los planes de ordenamiento territorial.

El incremento en este período de tiempo fue de 18 - 60 habitantes por hectárea a $180-270$ (como la planificada), pero el área de este último rango es mayor al área planificada con esa densidad. Cabe anotar que los lotes modificados en los planes fueron efectivamente modificados y transformados en equipamientos del sector, incluidos terrenos planificados para equipamientos comerciales, en donde posteriormente serían construidos los tres shopping centers: CCI, Quicentro y Mall El Jardín.

Figura 32. Densidad de población 1970, Quito

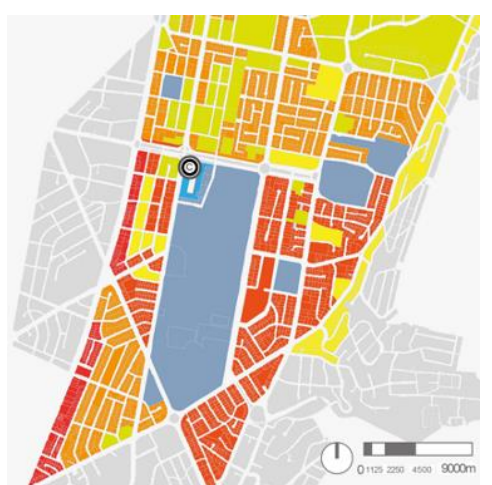

Fuente: Elaboración propia a partir del Plan Quito, 1980.

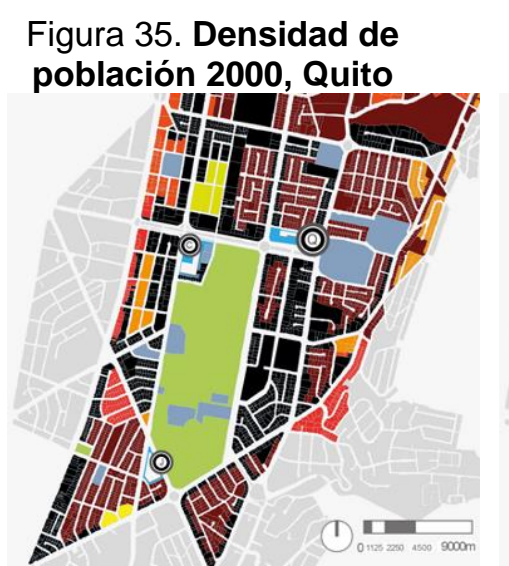

Fuente: Elaboración propia a partir del Plan Metropolitano de Ordenamiento Territorial 2012 2022, 2012.
Figura 33. Densidad de población 1980, Quito

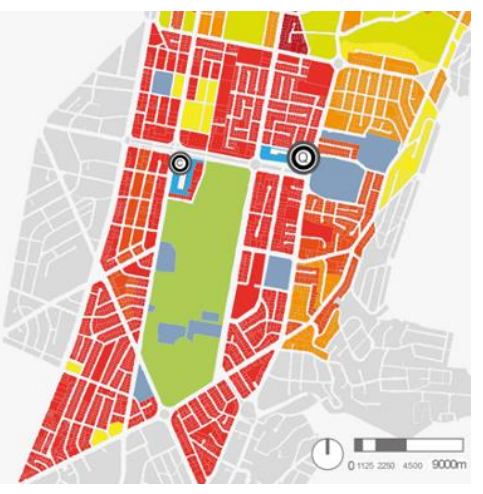

Fuente: Elaboración propia a partir del Plan de Estructura Urbana de Quito, 1990.

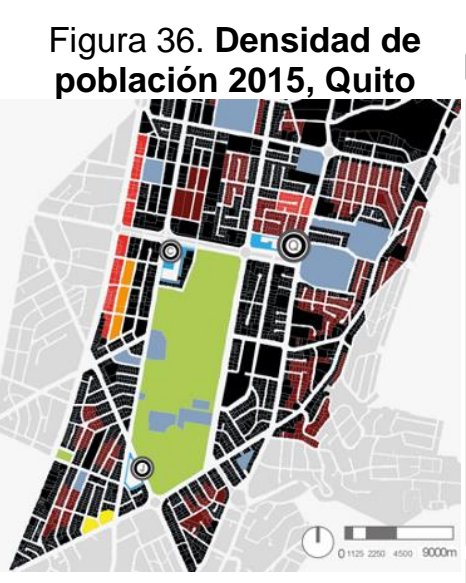

Fuente: Elaboración propia a partir del Plan de Desarrollo y de Ordenamiento Territorial, 2015.
Figura 34. Densidad de población 1990, Quito

En síntesis, estas cartografías revelan el incremento de densidad en el sector de Iñaquito planificado y construido y coinciden en que se trata de una de las zonas con mayor densidad de la ciudad y en la que se concentran 3 de los 8 shopping centers suprarregionales de Quito.

ACE@ AÑO 14, núm. 40, JUNIO 2019 | TRANSFORMACIONES DE LA CIUDAD Y EL SHOPPING CENTER - ANÁLISIS EN LA ESCALA 302 DEL SECTOR DE IÑAQUITO Y EL QUICENTRO SHOPPING CENTER EN QUITO 
Una vez más, debe resaltarse que al revés de lo postulado por el discurso que ve en el shopping center una amenaza, estos lugares no han aniquilado a la ciudad, al contrario, se evidencia que la densidad en el sector ha aumentado con el paso del tiempo.

\section{Edificabilidad / Zonificación}

En relación a la zonificación planificada, las Figuras 37-41 ilustran que, durante el periodo en estudio, se ha planificado el incremento de pisos en todo el sector.

\section{Figura 37. Edificabilidad en 1970, Quito}

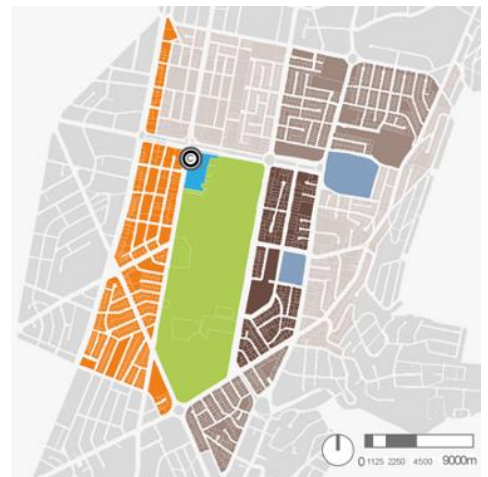

Fuente: Elaboración propia a partir del Plan Quito, 1980.

\section{Figura 40. Edificabilidad} en 2000, Quito

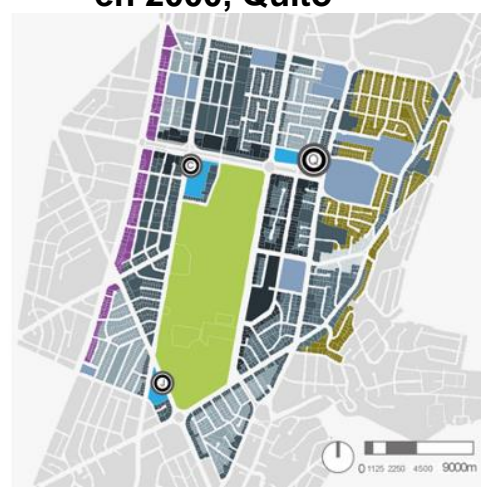

Fuente: Elaboración propia a partir del Plan Metropolitano de Ordenamiento Territorial 2012 2022, 2012.

\section{Figura 38. Edificabilidad en 1980, Quito}

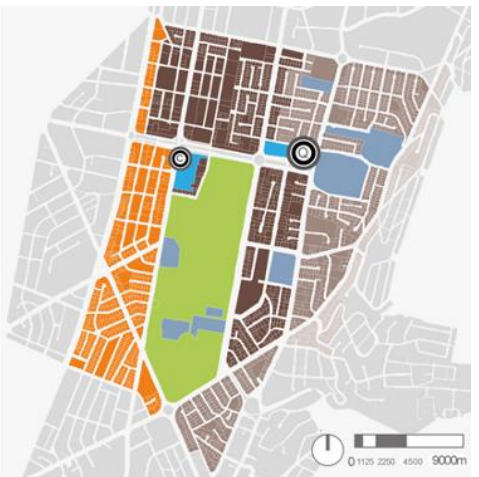

Fuente: Elaboración propia a partir del Plan de Estructura Urbana de Quito, 1990.

\section{Figura 41. Edificabilidad en 2015, Quito}

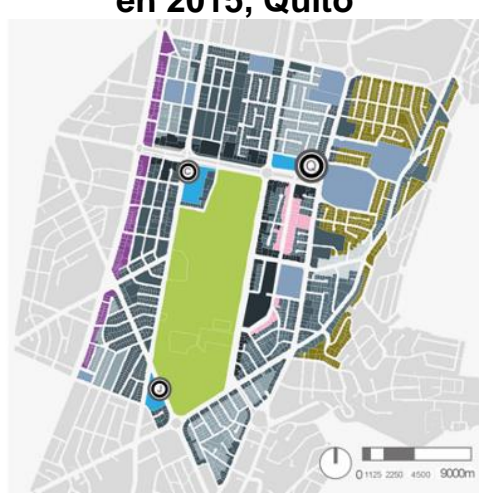

Fuente: Elaboración propia a partir del Plan de Desarrollo y de Ordenamiento Territorial, 2015.
Figura 39. Edificabilidad en 1990, Quito

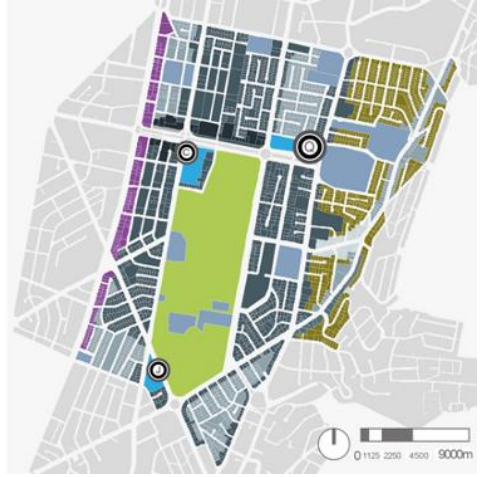

Fuente: Elaboración propia a partir del Plan General de Desarrollo Territorial 2000 - 2020, 2001.

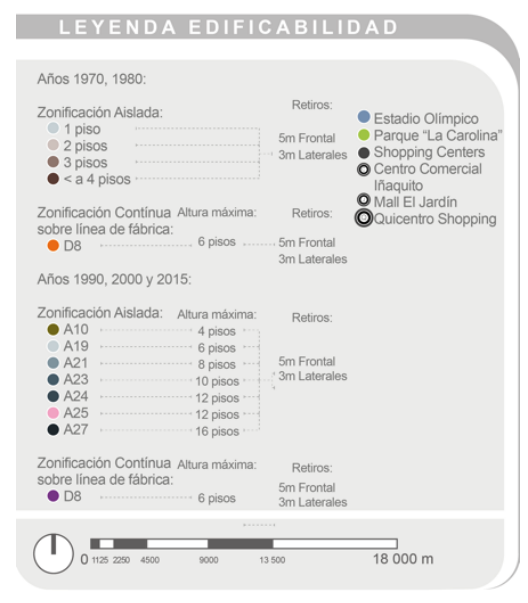

En lo que respecta a la efectiva zonificación y edificabilidad, en las Figuras $42-46$ se evidencia que el número de pisos no se ha elevado tanto como fue propuesto en el plan, no obstante, en todo el sector existió un aumento en la altura de las edificaciones. Los edificios más altos están localizados, ciertamente, en torno al Quicentro Shopping Center.

ACEO AÑO 14, núm. 40, JUNIO 2019 | TRANSFORMACIONES DE LA CIUDAD Y EL SHOPPING CENTER - ANÁLISIS EN LA ESCALA 302 DEL SECTOR DE IÑAQUITO Y EL QUICENTRO SHOPPING CENTER EN QUITO 
Figura 42. Edificabilidad en 1970, Quito

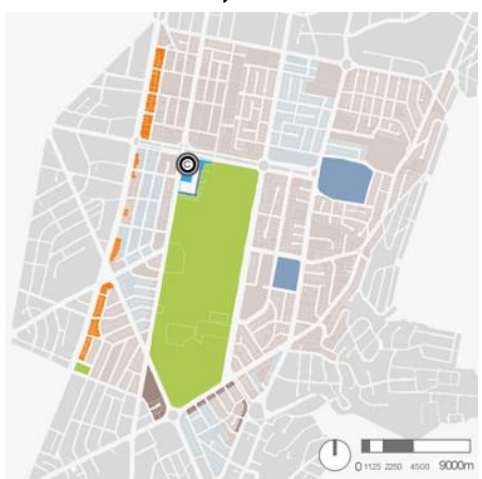

Fuente: Elaboración propia a partir del Plan Quito, 1980

Figura 45. Edificabilidad 2000, Quito

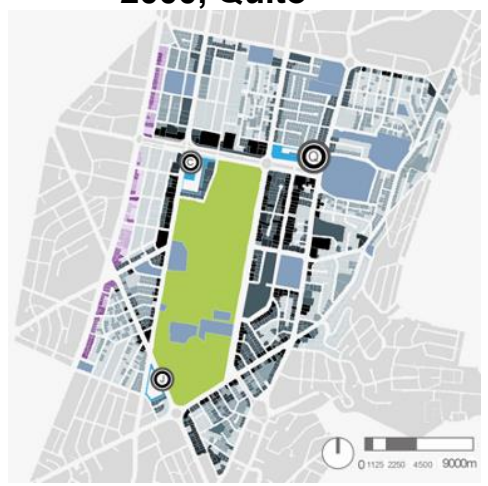

Fuente: Elaboración propia a partir del Plan Metropolitano de Ordenamiento Territorial 2012 2022, 2012.
Figura 43. Edificabilidad en 1980, Quito

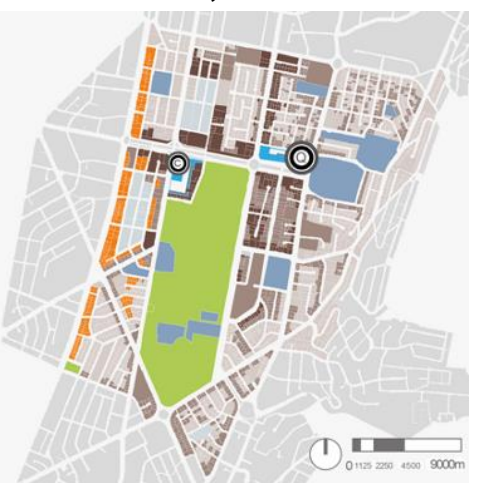

Fuente: Elaboración propia a partir del Plan de Estructura Urbana de Quito, 1990.

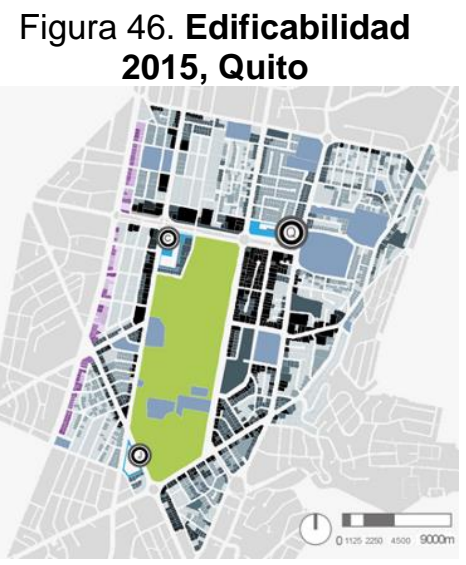

Fuente: Elaboración propia a partir del Plan de Desarrollo y de Ordenamiento Territorial, 2015.
Figura 44. Edificabilidad en 1990, Quito

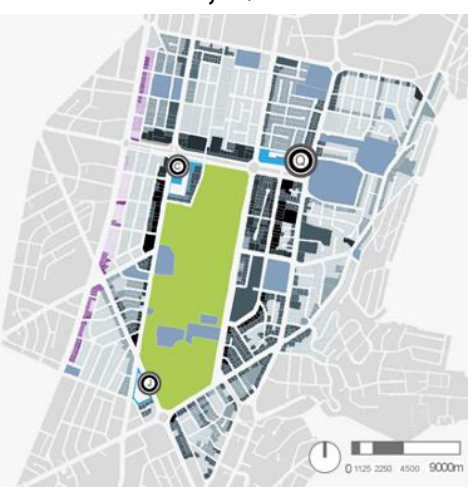

Fuente: Elaboración propia a partir del Plan General de Desarrollo Territorial 2000 - 2020, 2001.

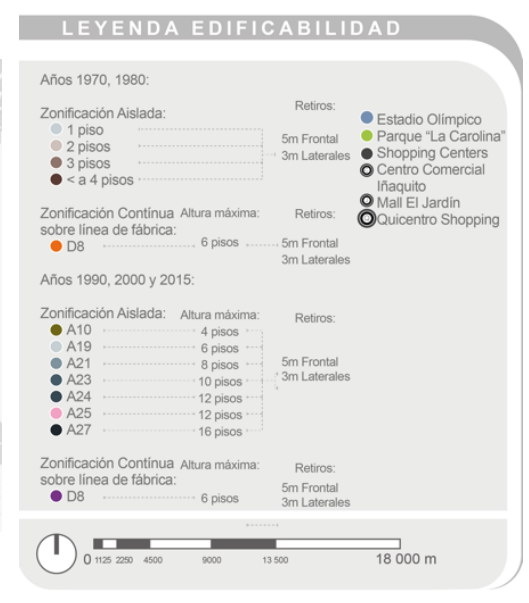

En las Figuras 37 y 38 se advierte que los planes de 1970 y 1980 proponen en el sector un máximo de 4 pisos, y la forma de ocupación es continua en línea de fábrica y aislada con retiros. A partir del plan de los años 1990 (Figura 39) se impulsa edificaciones de hasta 16 pisos y la forma de todo el sector es aislada con retiro frontal $(5 \mathrm{~m})$, laterales $(3 \mathrm{~m})$ y posterior (3m).

En la década del 70, el sector estaba ocupado por edificaciones de uno y dos pisos, en su mayoría (Figura 42). Existía al oeste del sector una hilera en sentido norte-sur con 6 pisos y un área concentrada en el sur del parque La Carolina con edificaciones de 3 pisos. Ya para los años 80 , la altura del sector se incrementa, se modifica el microparcelamiento y se pueden observar algunas edificaciones de 3 y 4 pisos en el sector (Figura 43). Todas las edificaciones en este período de tiempo tenían retiro frontal de 3 metros.

A partir del plan de 1990 hasta el año 2015 (Figuras 44-46), se edificaron construcciones de hasta 12 pisos y la forma de ocupación de la mayor parte del sector es aislada con retiro frontal $(5 \mathrm{~m})$, laterales $(3 \mathrm{~m})$ y posterior $(3)$.

ACEO AÑO 14, núm. 40, JUNIO 2019 | TRANSFORMACIONES DE LA CIUDAD Y EL SHOPPING CENTER - ANÁLISIS EN LA ESCALA 302 DEL SECTOR DE IÑAQUITO Y EL QUICENTRO SHOPPING CENTER EN QUITO 
Vale la pena señalar que la inserción de Centro Comercial Iñaquito y del Quicentro Shopping Center no limitó el crecimiento en altura de las edificaciones (buscando mayor densificación y consolidación de un nuevo centro financiero, residencial, de servicios y comercial de la ciudad).

\section{Quicentro Shopping Center: una extensión de la ciudad apropiada}

En el análisis que se expone más abajo, se busca evidenciar esta relación shopping center sector de Iñaquito, considerando su planificación, construcción y vivencia, desde la perspectiva de las trasformaciones en la forma, los usos y las formas de apropiación del QSC y su entorno inmediato.

Para corroborar y complementar los datos obtenidos empíricamente con la observación participación in situ, se realizaron encuestas a 372 usuarios del Quicentro, a 418 habitantes del sector y a 367 personas que trabajan en el sector.

A partir de las cartografías y los datos obtenidos en levantamientos y encuestas, se examina la efectiva relación que existe entre la forma, los usos y las formas de apropiación del Quicentro y su entorno inmediato, desde su planificación, construcción y apropiación.

\subsection{Forma, usos y apropiación.}

En este capítulo se presenta el análisis ejecutado a los levantamientos de la observación y participación in situ, a los datos obtenidos de las axonometrías y a los resultados de las encuestas mencionadas, buscando evidenciar la efectiva relación shopping center - entorno inmediato, desde su planificación, construcción y vivencia.

\section{El elemento Quicentro Shopping Center.}

El actual Quicentro Shopping Center tiene un total de área de construcción de 93.000 metros cuadrados, 85.000 metros cuadrados de GLA (gross leasable area o área bruta para ventas), 210 locales comerciales con variedad de productos y marcas internacionales y nacionales. Este shopping center fue insertado en el centro financiero de Quito y desde su concepción "salió" de la escala del objeto arquitectónico, proyectándose como un espacio urbano que cubrió las necesidades humanas básicas, incluyendo el encuentro y las actividades colectivas (Michel Deller, comunicación personal, enero de 2016). En este sentido, desde su origen el QSC ha programado una diversa gama de actividades y eventos paralelos a las ventas de los locales comerciales y a los servicios.

Las diferentes formas, usos y formas de apropiación del Quicentro Shopping Center pudieron ser analizadas en esta investigación a partir de varias visitas al sitio, en diferentes horarios y días, para la observación directa y participación de las actividades del shopping center.

Como antecedente, es importante resaltar que el Quicentro fue transformado de nuevo, espacial y programáticamente en el año 2012 (Figuras 47 y 48) y esas modificaciones han fortalecido el nexo más directo entre su interior y su entorno y, asimismo, han intensificado su grado de apropiación. 
Figura 47. Quicentro, antes de 2012

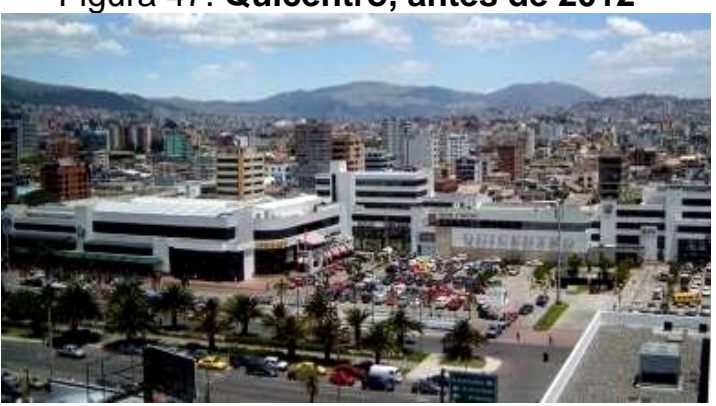

Fuente: recurso electrónico²
Figura 48. Quicentro actual, 2017

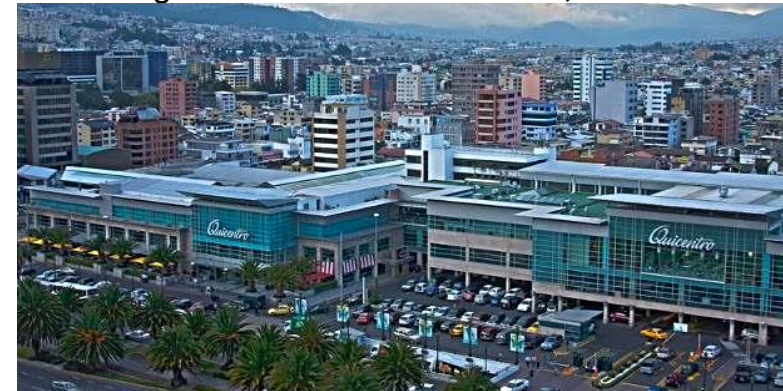

Fuente: recurso electrónico

Entre las aquellas últimas transformaciones del Quicentro se destacan: El acristalamiento de toda la fachada sur (Figuras 49 y 50), que permite el diálogo visual con el nuevo Bulevar Naciones Unidas (esta fachada siempre tuvo una intención de transparencia y vinculación con el entorno, que fue intensificada con las intervenciones más recientes).

Figura 49. Acristalamiento de la fachada sur del Quicentro

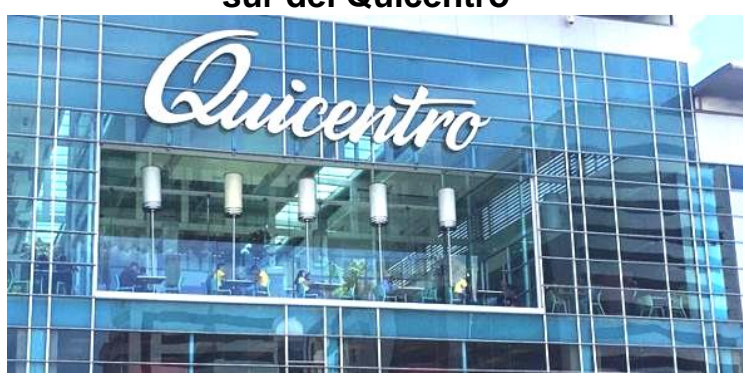

Fuente: Autor, 2016.
Figura 50. Visuales desde el interior del QSC hacia su entorno sur

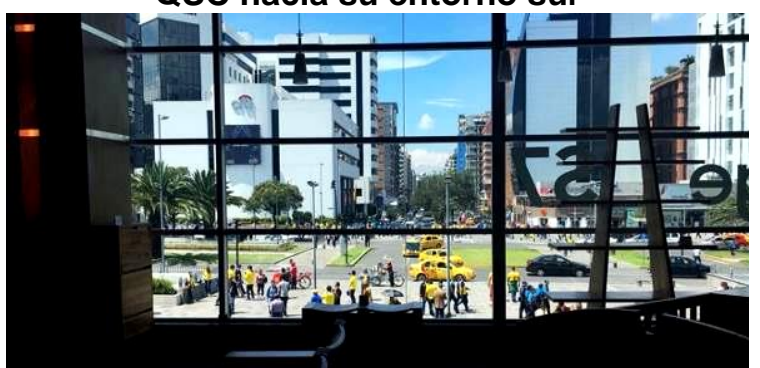

Fuente: Autor, 2016.

En las Figuras 51 y 52, se puede observar la misma fachada sur (principal) acristalada del Quicentro, cuyas características efectivamente facilitan la relación visual con su entorno inmediato. Además, en esta fachada se ubican algunos ingresos peatonales, incluyendo el acceso principal desde el Boulevard Naciones Unidas y a algunas cafeterías que están dispuestas en directa relación con el espacio público. Por el contrario, la fachada norte constituye un muro ciego con un solo ingreso que restringe el diálogo con la ciudad (Figura 53).

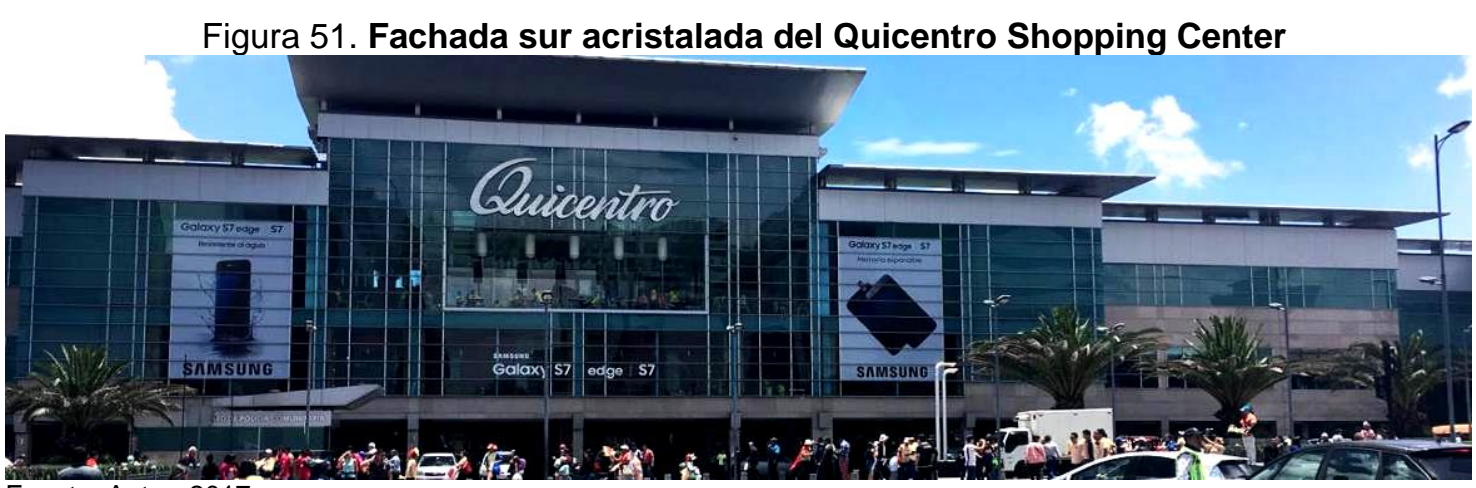

Fuente: Autor, 2017

${ }^{2}$ http://mw2.google.com/mw-panoramio/photos/medium/3192569.jpg; 2017-05-25 15h25

3 http://img823.imageshack.us/img823/6361/tone33012.jpg; 2017-05-25 15:30

ACE@ AÑO 14, núm. 40, JUNIO 2019 | TRANSFORMACIONES DE LA CIUDAD Y EL SHOPPING CENTER - ANÁLISIS EN LA ESCALA 303 DEL SECTOR DE IÑAQUITO Y EL QUICENTRO SHOPPING CENTER EN QUITO 


\section{Figura 52. Axonometrías de emplazamiento e ingresos al Quicentro Shopping Center}

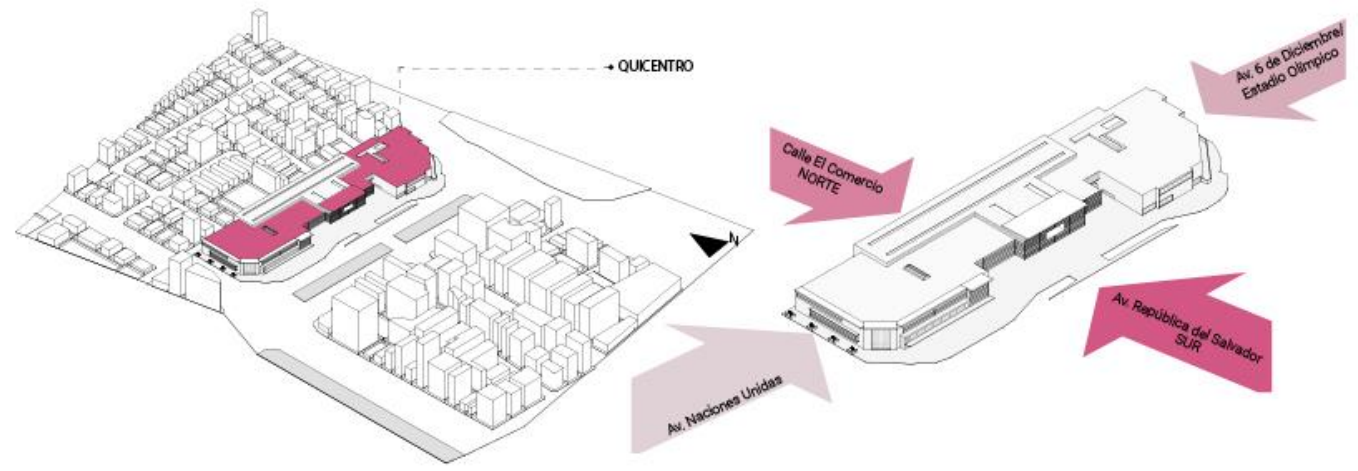

Fuente: Elaboración propia a partir de mapa de diagnóstico de Plan de Ordenamiento Territorial 2015 y con plantas esquemáticas del Quicentro Shopping Center.

Figura 53. Fachada sur (muro ciego con portón de ingreso) Quicentro Shopping Center

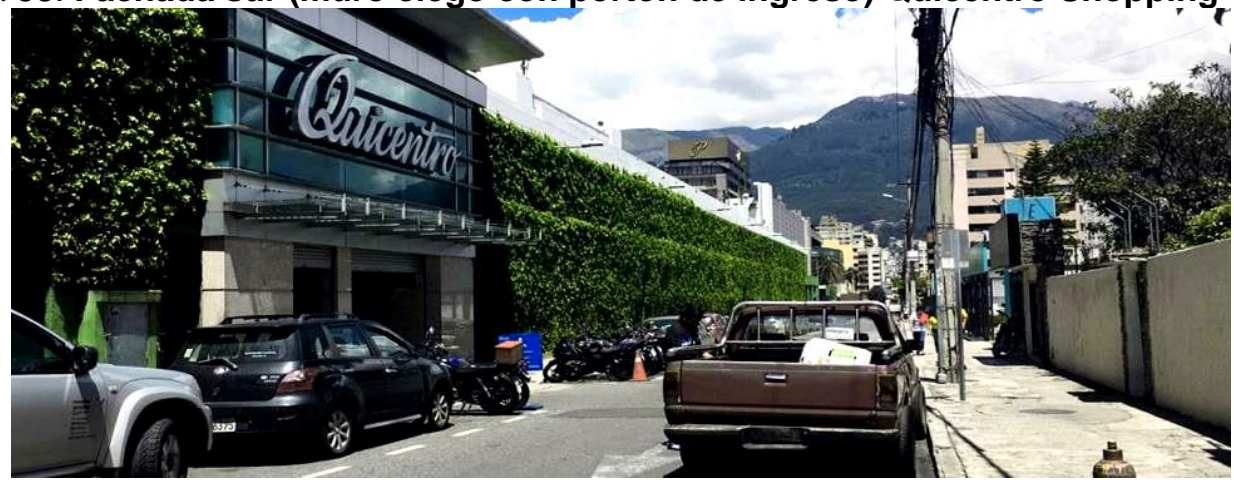

Fuente: Autor, 2017

En las Figuras 54-56 se logra evidenciar el grado de permeabilidad que tienen las diferentes fachadas del QSC. En la planta baja (Figura 54), puede apreciarse que la mayoría de ingresos están localizados en la fachada sur y que la permeabilidad visual también permite la interrelación entre el shopping center y su entorno. De forma inversa, se advierte, en la misma Figura 54, que existe únicamente un portón de ingreso a la fachada norte en la planta baja, lo cual, desde luego, disminuye el diálogo entre el QSC y su entorno inmediato al norte.

Figura 54. Permeabilidad QSC. Planta baja

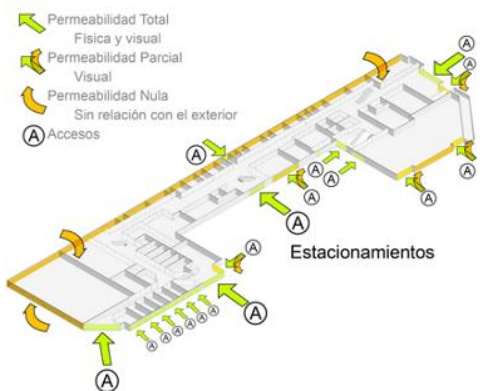

Fuente: Elaboración propia a partir de plano del QSC y observación en sitio.

\section{Figura 55. Permeabilidad QSC. Primera Planta}

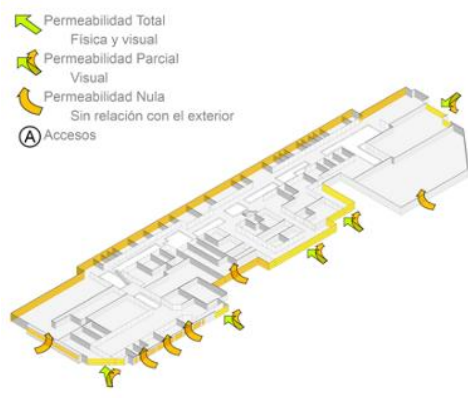

Fuente: Elaboración propia a partir de plano del QSC y observación en sitio.

\section{Figura 56. Permeabilidad QSC. Segunda Planta}

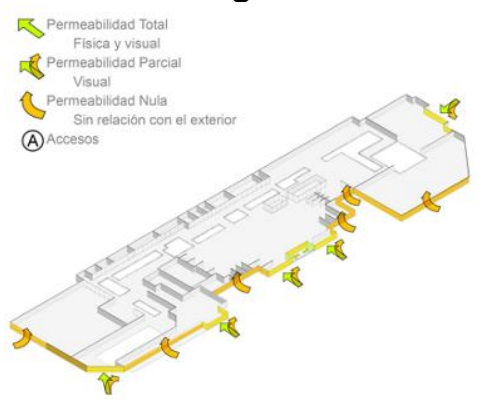

Fuente: Elaboración propia a partir de plano del QSC y observación en sitio. 
En la figura 54 de la planta baja del QSC se puede observar tiene membranas permeables que permiten la relación visual entre el shopping center y su entorno inmediato. El corredor de cafeterías y restaurantes, cuyas puertas se abren al Boulevard Naciones Unidas (Figura 57), constituye otro espacio que presenta una alta apropiación por parte de los usuarios del Quicentro. Es un área con sombrillas donde la gente puede tomar un café o comer al aire libre.

\section{Figura 57. Fotografía de las cafeterías y restaurantes que tienen sus puertas de ingreso} hacia el Boulevard Naciones Unidas, al sur del Quicentro

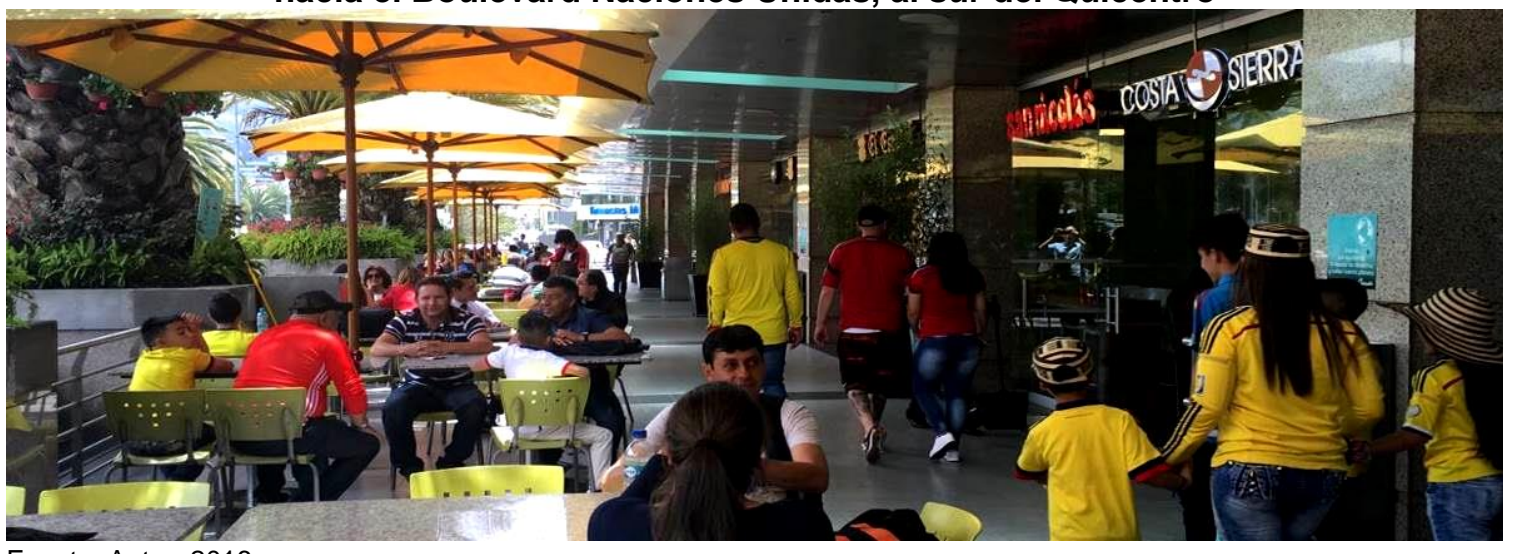

Fuente: Autor, 2016.

En términos de la efectiva apropiación que la zona experimenta por parte de la población, se ha analizado las actividades generadas en el entorno del Quicentro Shopping Center para evidenciar este proceso y verificar si efectiva y específicamente el shopping center incentiva la apropiación del espacio urbano de su entorno.

En ese contexto, la Figura 58 (mapeo realizado de todo el sector Iñaquito en la actualidad a partir de observación in situ) permite observar el alto grado de porosidad (Ellin, 2006) de las edificaciones del sector, el cual facilita la interrelación entre ellas y el espacio público. Cabe resaltar que hacia el sur del QSC el grado de porosidad es alto (Figura 59), sin embargo, hacia el norte este disminuye ya sea por falta de edificación (Figura 60) o por presencia de muros ciegos en la configuración del espacio público. También se ha levantado los puntos de mayor concentración de peatones (entre semana y fin de semana), de los cuales dos coinciden en el este y oeste del Quicentro Shopping Center (otros dos puntos coinciden con el Centro Comercial Iñaquito y con el Mall El Jardín).

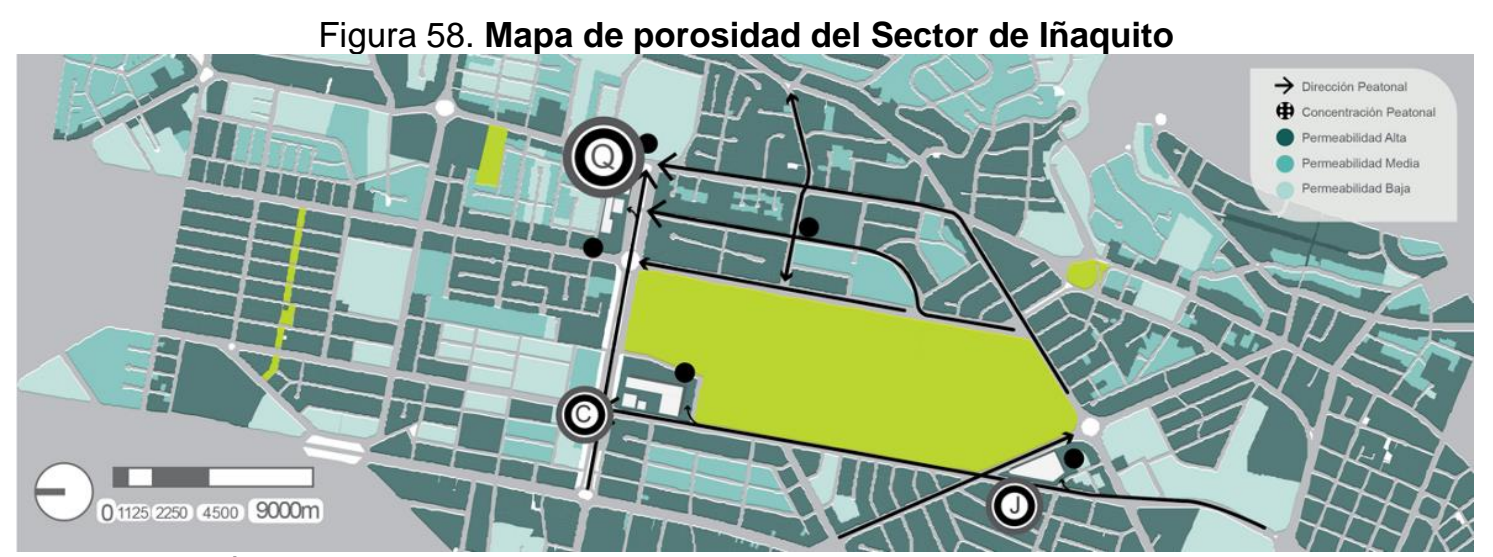

Fuente: Elaboración propia a partir levantamiento in situ, 2015.

ACE@ AÑO 14, núm. 40, JUNIO 2019 | TRANSFORMACIONES DE LA CIUDAD Y EL SHOPPING CENTER - ANÁLISIS EN LA ESCALA 302 
Figura 59. Locales comerciales de las edificaciones al sur del QSC en relación directa con la calle

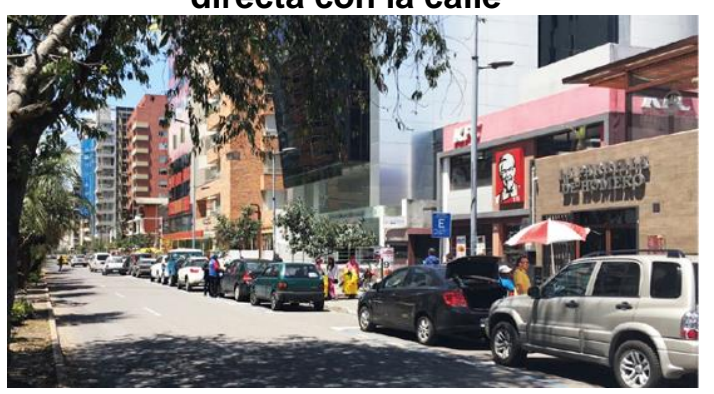

Fuente: Autor, 2015.
Figura 60. Lotes al norte del QSC, sin una relación con la calle que incentive su apropiación

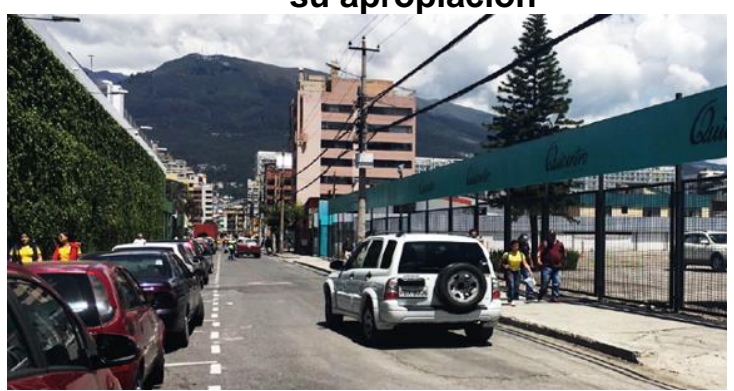

Fuente: Autor, 2015

En la Figura 61 se aprecia la configuración de la Av. República del Salvador que remata en el ingreso principal del Quicentro desde el sur. Se trata de edificaciones de hasta 12 pisos, con uso de suelo residencial múltiple; comercio en la escala del sector planta baja y algunas oficinas en las primeras plantas de algunos edificios. Se puede ver, en la vereda izquierda, las terrazas gastronómicas orientadas hacia la calle. Por la diversidad de usos, la relación entre edificación, espacio público y densidad, esta calle presenta un alto grado de apropiación durante el día, sobre todo en horarios de almuerzo de las oficinas.

Figura 61. Configuración de la Av. República del Salvador, al sur del Quicentro. Al fondo, el ingreso principal del QSC.

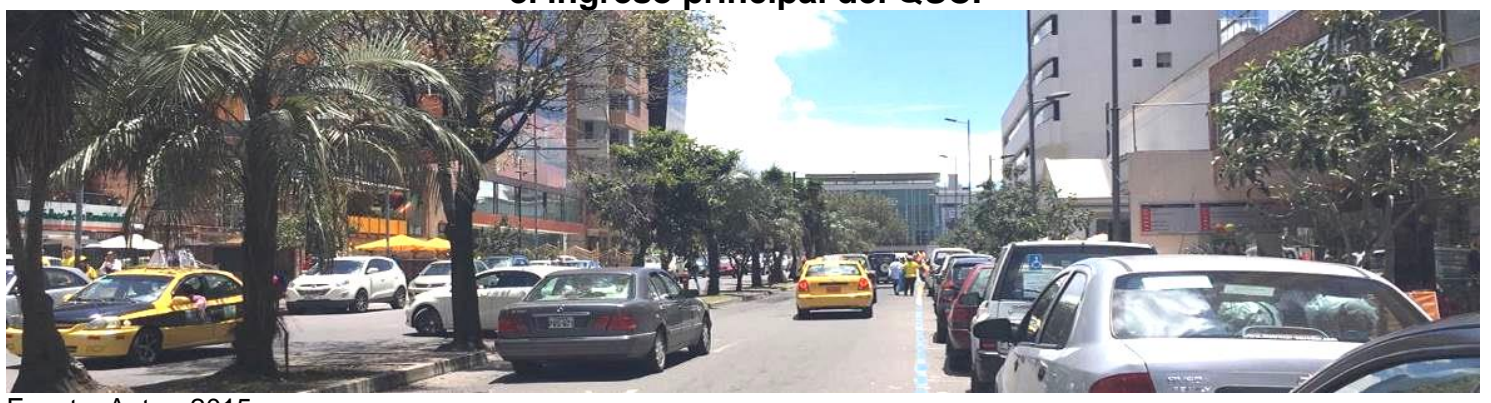

Fuente: Autor, 2015.

La Figura 62 revela que la calidad del diseño de las calles y avenidas en el entorno sur del QSC incentiva su apropiación por personas con movilidad reducida (discapacidad física para moverse). Además, hay bancas en las veredas y vegetación para cubrirse del sol, que contribuyen en tal sentido. Hay que indicar, asimismo, que se ha venido restringiendo el estacionamiento de vehículos medianet políticas que permiten un máximo de 2 horas pagadas.

Figura 62. Apropiación de calle del entorno sur del QSC

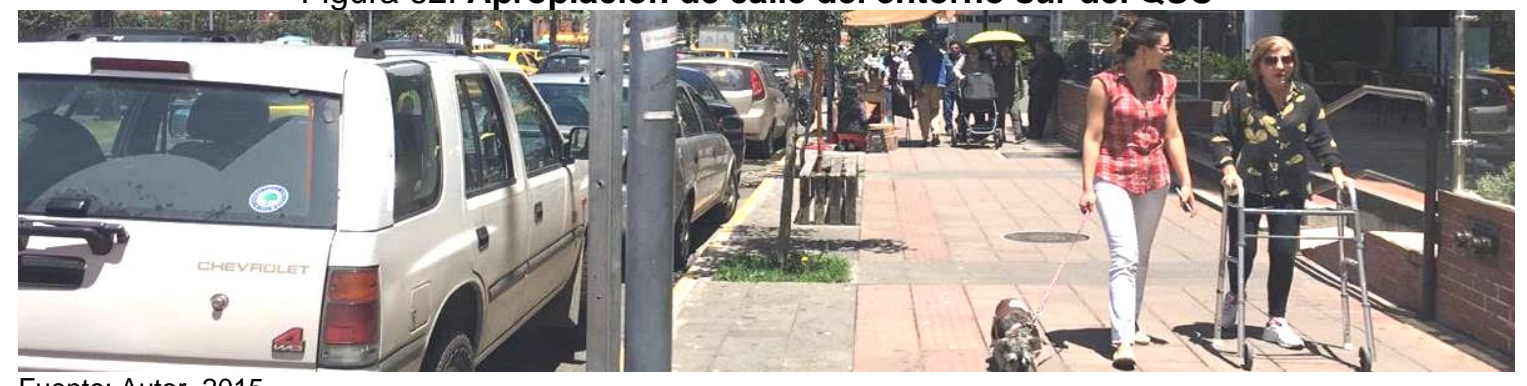

Fuente: Autor, 2015.

ACE@ AÑO 14, núm. 40, JUNIO 2019 | TRANSFORMACIONES DE LA CIUDAD Y EL SHOPPING CENTER - ANÁLISIS EN LA ESCALA 
$4 \begin{aligned} & \text { Architecture, City, and Environment } \\ & \text { Arquitectura, Ciudad y Entorno }\end{aligned}$

En la Figura 63 se puede percibir el grado de apropiación del Boulevard Naciones Unidas, durante un día sábado de agosto de 2015 (cuando se realizan exposiciones y presentaciones en el espacio público). La imagen corresponde a la visual desde el patio de comidas del QSC y constata la considerable cantidad de gente caminando por la calle.

Figura 63. Apropiación del frente sur del QSC y la Av. República del Salvador. Fotografía tomada desde el patio de comidas del Quicentro

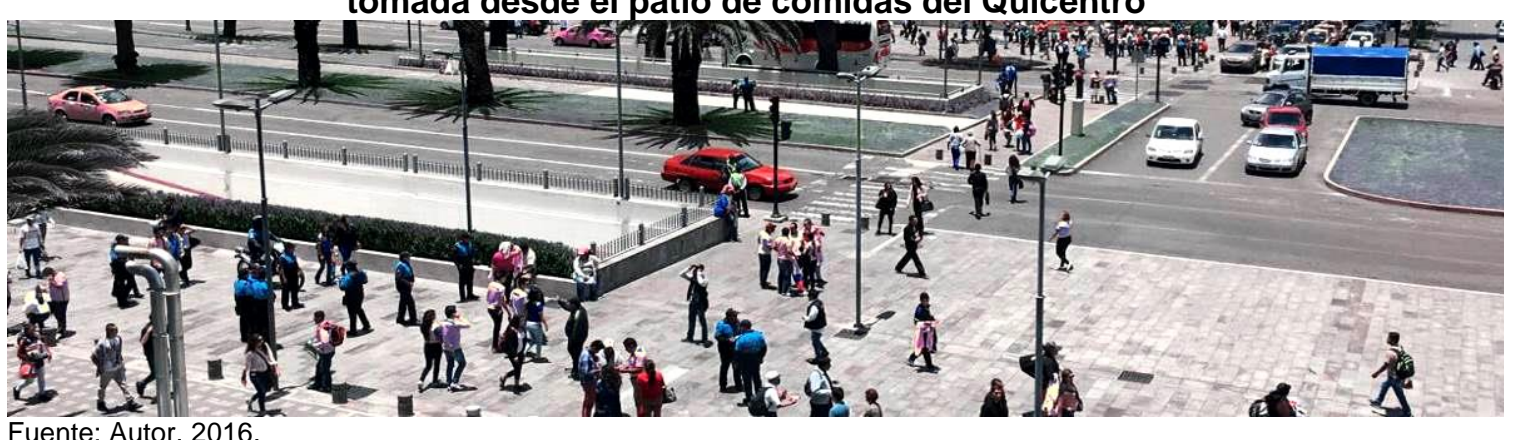

La Figura 64 demuestra el grado de apropiación del Boulevard Naciones Unidas en un día de concierto en el Estadio Olímpico Atahualpa, al este del Quicentro. Muchas personas ingresan al Quicentro para "hacer tiempo" (esperar a que sea hora del concierto) y pasear o comer algo. En las Figuras 65 y 66, que corresponden a la calle del entorno inmediato norte del Quicentro Shoppingc Center, se advierte el bajo grado de apropiación, debido a la poca relación existente entre el QSC y la calle. La baja porosidad y diversidad de usos en relación directa con el espacio público restringen la efectiva apropiación de este espacio puesto que no facilita el desarrollo de actividades que motiven dicho proceso.

Figura 64. Apropiación del frente sur del QSC y la Av. República del Salvador. Fotografía del ingreso principal del QSC, tomada desde el Boulevard Naciones Unidas

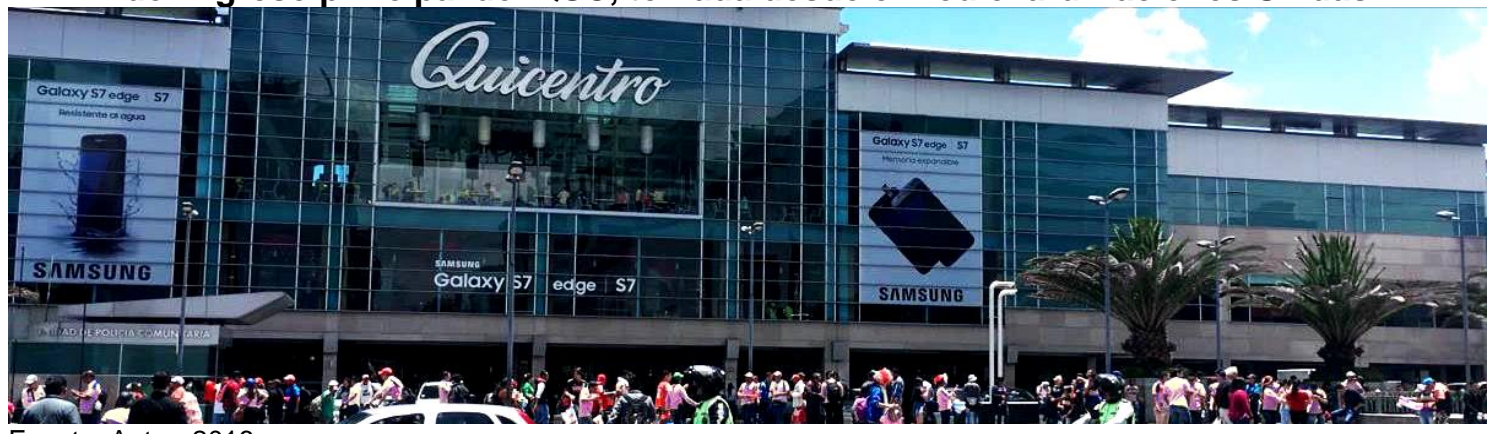

Fuente: Autor, 2016.

Figura 65. Calle El Comercio, al norte del Quicentro, configurada por muros ciegos (a la izquierda muro ciego del QSC)

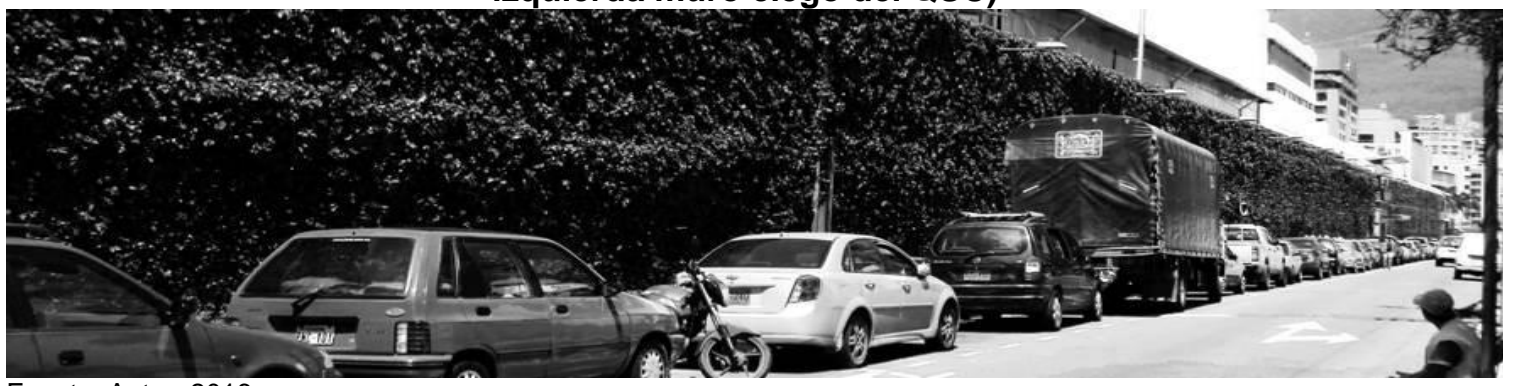

Fuente: Autor, 2016.

| TRANSFORMACIONES DE LA CIUDAD Y EL SHOPPING CENTER - ANÁLISIS EN LA ESCALA 302 
Figura 66. Calle El Comercio, al norte del Quicentro, configurada por muros ciegos (a la izquierda muro ciego del QSC)

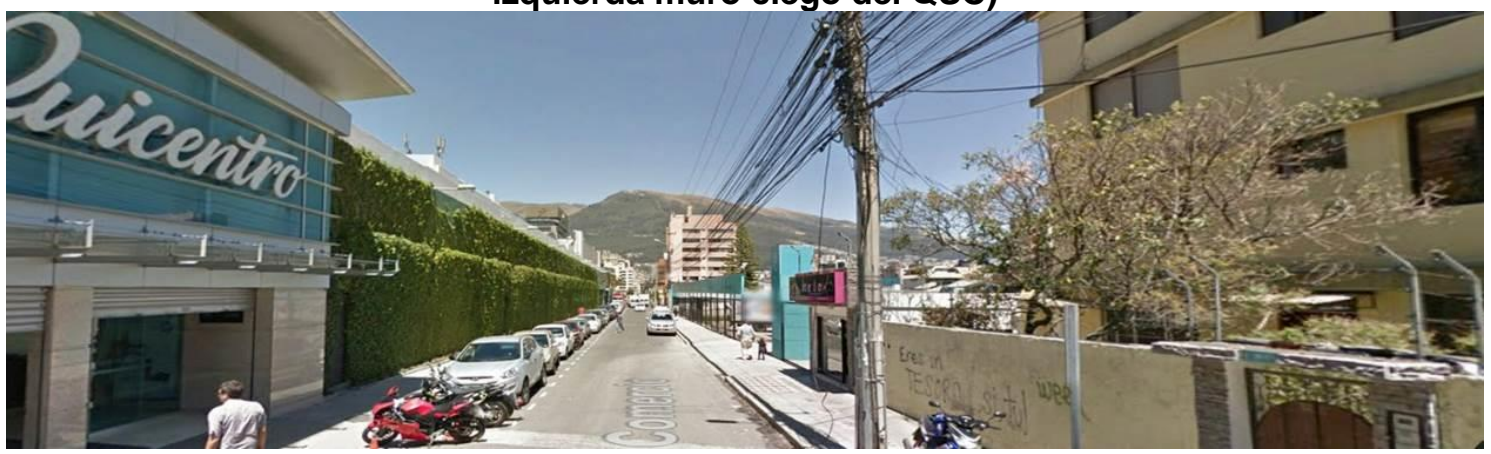

Fuente: Captura de pantalla de Google Maps, 2016.

En la Figura 67 se puede ver la calle El Vengador, que remata en el ingreso norte del Quicentro. Las edificaciones aisladas en el lote tienen muros o cercas que configuran el espacio público, restringiendo su grado de apropiación al no permitir una relación directa entre la calle y las edificaciones. La poca diversidad de uso de suelo (residencial 3) no facilita la diversidad y concentración de usuarios para mantener este espacio ocupado. Esto ha traído algunos problemas de inseguridad puesto que es un espacio que no posee vigilancia natural.

Figura 67. Calle El Vengador, al norte del Quicentro, configurada por muros ciegos y cercas.

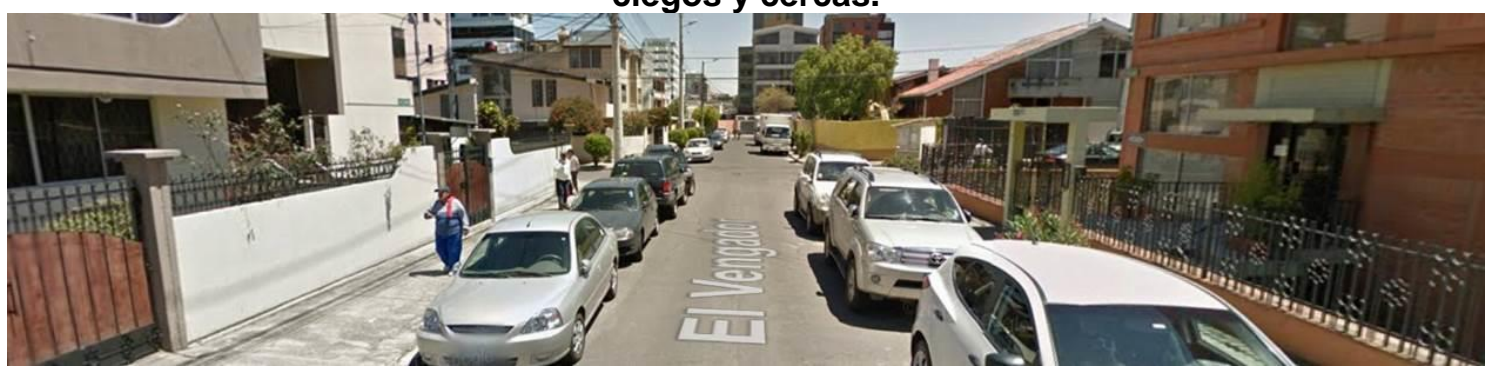

Fuente: Captura de pantalla de Google Maps, 2016.

De hecho, en la Figura 68 se aprecia uno de los mecanismos de defensa que han adoptado los moradores del entorno norte del QSC para evitar robos y asaltos. Han cercado la calle, restringiendo el acceso a personas que no viven en ella; a pesar de no ser legal puesto que privatizan un espacio público, han preferido pagar multas hasta que el municipio garantice la seguridad de estos barrios. De igual manera, se puede ver la garita de guardianía privada en la esquina de la calle, que busca entregar mayor vigilancia a las calles.

Figura 68. Calles privatizadas con cercas debido a los niveles de inseguridad

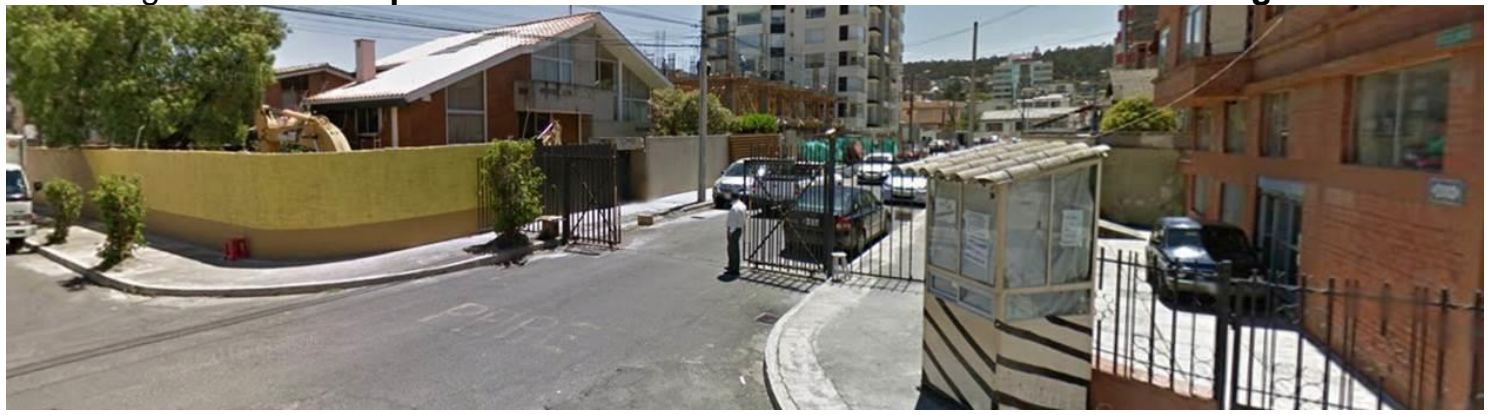

Fuente: Captura de pantalla de Google Maps, 2016.

ACE@ AÑO 14, núm. 40, JUNIO 2019 | TRANSFORMACIONES DE LA CIUDAD Y EL SHOPPING CENTER - ANÁLISIS EN LA ESCALA 303 DEL SECTOR DE IÑAQUITO Y EL QUICENTRO SHOPPING CENTER EN QUITO 
Recapitulando, el análisis aquí expuesto sobre el espacio vivido del Quicentro Shopping Center y su entorno inmediato, ha permitido evidenciar cómo se planificó y materializó la ciudad desde 1970 hasta 2015, con relación a la inserción del Quicentro. Así también, el estudio constató la dialéctica que existe entre la inserción del Quicentro Shopping Center y las transformaciones de su entorno inmediato en relación a su morfología, usos y apropiación.

\section{Encuestas}

Para cotejar la información expuesta previamente y levantada a partir de la observación y participación en in situ, se procedió a realizar encuestas a usuarios del Quicentro, a habitantes del sector y a personas que trabajan allí. Los resultados de las encuestas a 372 usuarios del Quicentro Shopping Center se han graficado en la Figura 69. Las muestras mantuvieron un equilibrio entre niños, jóvenes y adultos, y hombres y mujeres.

\section{Figura 69. Infografía de resultados de las encuestas a usuarios del QSC}

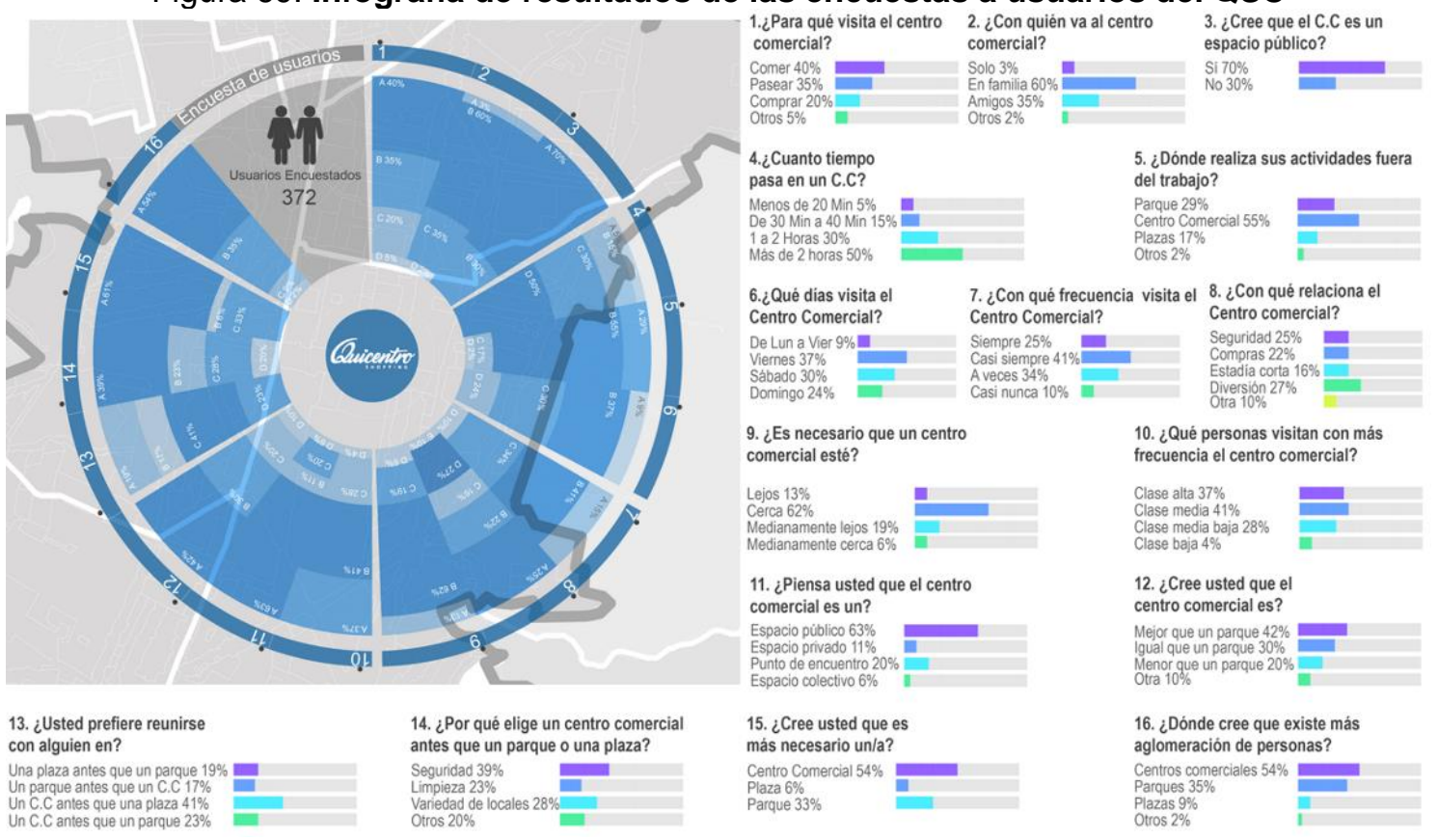

Fuente: Elaboración propia a partir encuestas, 2016.

Los resultados de las encuestas que ayudan a complementar de forma cuantitativa las descripciones de la observación y participación in situ, son los siguientes:

- La mayoría de los encuestados asegura que en los shopping centers existe mayor concentración de personas que en los espacios públicos, además de considerarlos más necesarios.

- La diversidad de actividades, la seguridad y la limpieza son condiciones que hacen preferir un shopping center a un espacio público. Además, la mayoría de gente lo visita en familia y con amigos como espacio de entretenimiento y encuentro.

- Un 70\% de los usuarios conciben al Quicentro Shopping Center como un espacio público, pues lo consideran un lugar óptimo para comer y pasear. Sólo un $20 \%$ del total de la muestra asiste al mall únicamente para hacer compras.

- Más del $65 \%$ de usuarios visita con frecuencia el shopping center (aunque la mayoría va los días viernes) y estiman que sus usuarios corresponden predominantemente a personas de clase alta y media.

ACE@ AÑO 14, núm. 40, JUNIO 2019 | TRANSFORMACIONES DE LA CIUDAD Y EL SHOPPING CENTER - ANÁLISIS EN LA ESCALA 304 DEL SECTOR DE IÑAQUITO Y EL QUICENTRO SHOPPING CENTER EN QUITO 
La Figura 70, en tanto, exhibe los resultados de las encuestas a 418 habitantes del sector donde está insertado el Quicentro Shopping Center. Las muestras mantuvieron un equilibrio entre jóvenes y adultos, y hombres y mujeres. No se realizaron encuestas a niños puesto que sus acompañantes lo vieron como una amenaza a su seguridad. Esto también fue una pista de la diferencia entre la percepción de seguridad dentro y fuera del QSC. Además, las encuestas fueron efectuadas en diferentes lugares del sector, hacia el norte y el sur del Quicentro. Sin embargo, se pudieron concretar más encuestas en el entorno sur del Quicentro porque había mayor cantidad de personas.

Figura 70. Infografía de resultados de las encuestas a habitantes del sector

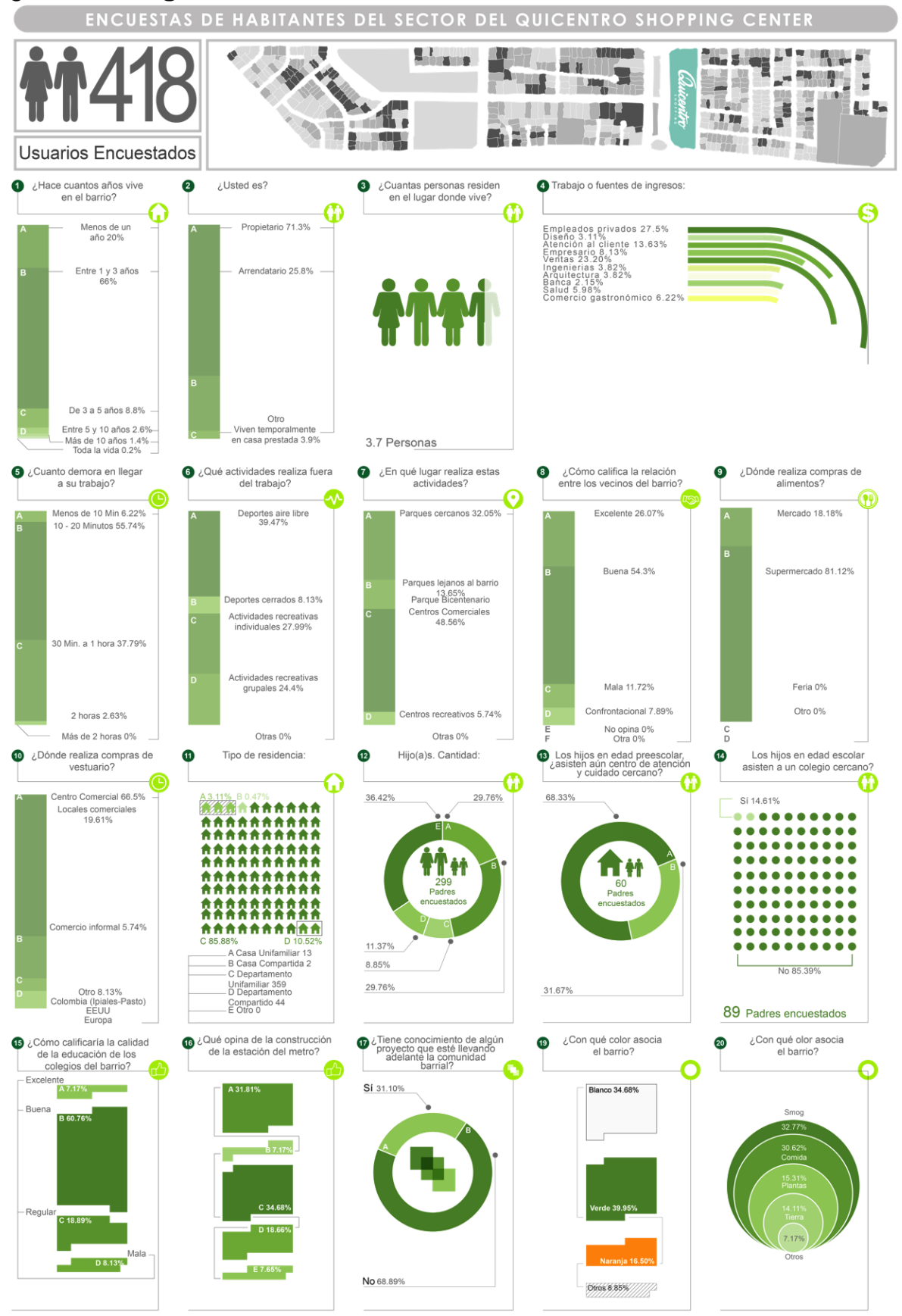

Fuente: Elaboración propia a partir de encuestas, 2016.

ACE@ AÑO 14, núm. 40, JUNIO 2019 | TRANSFORMACIONES DE LA CIUDAD Y EL SHOPPING CENTER - ANÁLISIS EN LA ESCALA 305 DEL SECTOR DE IÑAQUITO Y EL QUICENTRO SHOPPING CENTER EN QUITO 
Los resultados de las encuestas que complementan de forma cuantitativa las descripciones obtenidas de la observación y participación in situ expuestas, se indican a continuación:

- La mayoría de gente vive en el sector desde hace uno a tres años, lo que denota que existe una alta rotación de moradores, no obstante, más del $70 \%$ son propietarios de los bienes inmuebles. A pesar de esta rotación, más del $50 \%$ considera que la relación con sus vecinos es buena y alrededor de un $25 \%$ considera que es excelente.

- Más del $80 \%$ de los habitantes realizan sus compras en el supermercado del Quicentro.

- Cerca del 60\% de los habitantes se tardan en llegar a sus trabajos entre 10 y 20 minutos, lo que sugiere que ellos buscan vivienda cerca de sus trabajos y, desde luego, que trabajan en el sector.

- Casi el 50\% de la muestra realiza sus actividades fuera del trabajo (y de su casa) en el shopping center.

En la Figura 71 se han registrado los resultados de las encuestas a 367 habitantes del sector donde se ubica el Quicentro Shopping Center. Las muestras se realizaron a un $38 \%$ de hombres (jóvenes y adultos) y a un $62 \%$ de mujeres (jóvenes y adultas). Asimismo, las encuestas fueron ejecutadas en diferentes zonas del sector, incluyendo el QSC.

Figura 71. Infografía de resultados de encuestas a personas trabajadoras del sector PERSONAS QUE TRABAJAN EN EL BARRIO

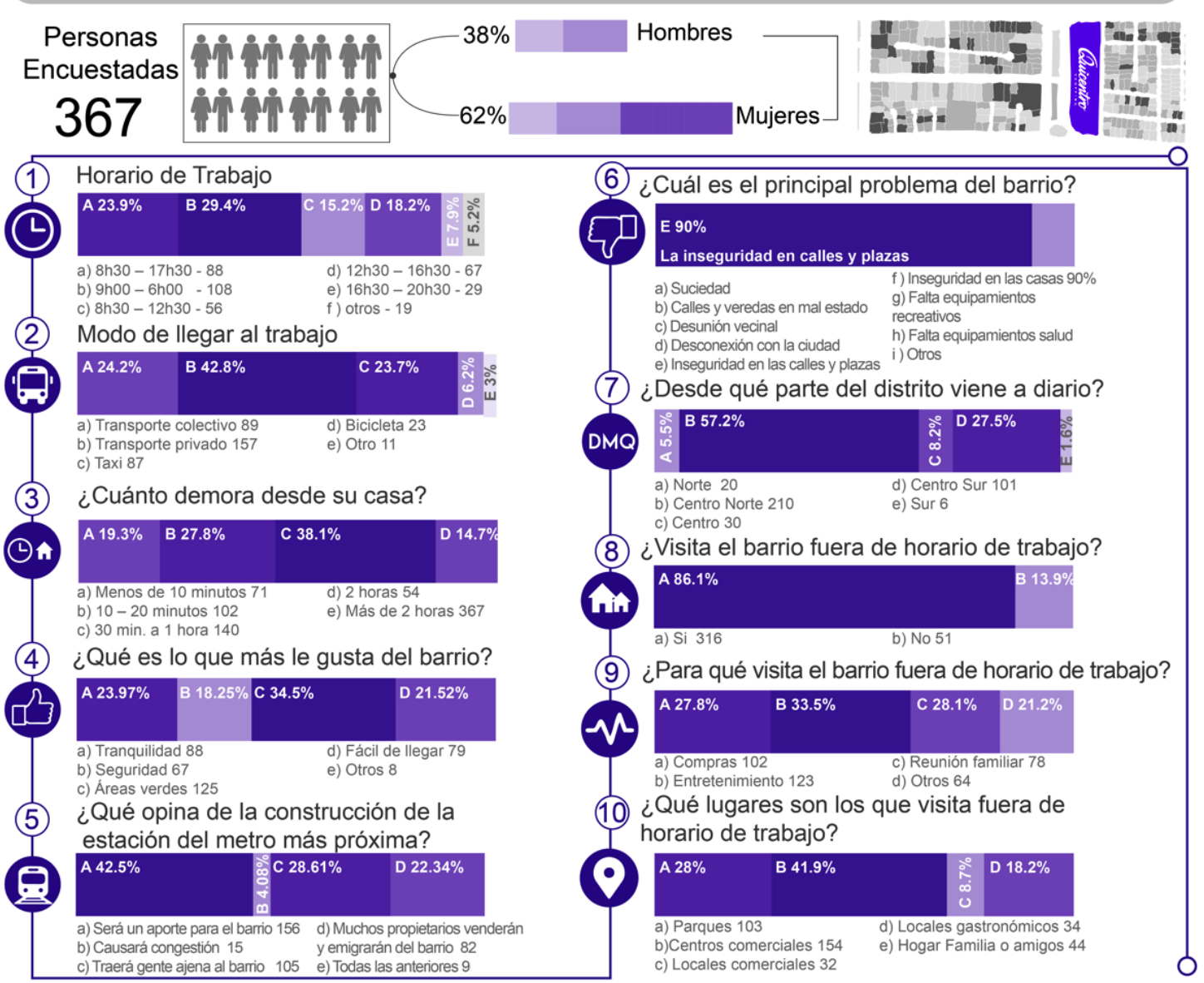

Fuente: Elaboración propia a partir de encuestas, 2016. 
Al igual que en el segmento anterior, los resultados de las encuestas que contribuyen a complementar de forma cuantitativa las descripciones de la observación y participación in situ señaladas en el trabajo, fueron los siguientes:

- Más del $40 \%$ de la gente se transporta en vehículo privado hacia el sector para trabajar, y cerca del $25 \%$, en transporte colectivo. Cerca del $40 \%$ se tarda entre 30 minutos y una hora en trasladarse a su lugar de trabajo, lo que indica que no viven en el sector y provienen de otros lugares de la ciudad (cerca del 60\% del centro-norte de Quito).

- Estas personas consideran positiva la opción de trasladarse en metro hacia sus trabajos cuando esté terminado, pues más del $40 \%$ piensa que será un aporte para el barrio.

- Se estima que el principal problema del barrio es la inseguridad en el espacio público, sin embargo, más del $85 \%$ de encuestados visita el sector fuera del horario del trabajo para realizar compras, actividades de entretenimiento y reunirse con sus familias. De tal modo, más del $40 \%$ afirmó visitar el shopping centers fuera del horario de trabajo.

Como conclusión general del análisis de este capítulo, se puede sostener que la concepción espacial y programática del QSC y su construcción como un elemento diverso lo han convertido en un importante espacio de sociabilidad y encuentro. Además, su tipología permeable que fomenta su conexión con la ciudad ha repercutido en la intensificación del grado de apropiación, por parte de los usuarios, de su entorno inmediato y del mismo shopping center.

En lo que sigue se expondrán las conclusiones finales de la tesis.

\section{Conclusiones}

\subsection{Tendencias del shopping center contemporáneo. Evidencias}

El shopping center ha debido mutar, tanto espacial como programáticamente, debido a los cambios sociales desarrollados desde su concepción original. La llamada sociedad del consumo contemporánea busca no únicamente el consumo de bienes o productos, sino de situaciones y experiencias en un espacio urbano donde puedan ser observados. Estas experiencias han venido ocurriendo en espacios del shopping center, que tienen hoy un valor y significado de identidad social; imitan a la ciudad e, incluso, diluyen y confunden el límite entre la ciudad y el shopping center.

La tendencia de "demallizar" el shopping center (abrirlo hacia la ciudad) planteada por el International Council de Shopping Centers (2000) propone disminuir el encierro para reducir la percepción segregadora, excluyente y discriminatoria que envolvía a la "caja cerrada", para convertirla en un espacio urbano con un conjunto de calles y plazas públicas a cielo abierto. No todos los shopping centers contemporáneos tienen en la actualidad una lectura tradicional de mall cerrado y hermético, puesto que presentan un margen difuso entre lo exterior e interior 0 entre lo público y lo privado, el consumo y la experiencia del lugar, dada las relaciones que posibilitan con la ciudad y por las actividades que albergan en sus instalaciones.

El Quicentro Shopping Center desde su origen, fue proyectado como una arquitectura permeable que ha favorecido la relación con la ciudad a través de la transparencia y porosidad de su fachada principal, la que facilita una mayor infiltración de la ciudad hacia el shopping center, y viceversa, logrando que el grado de vitalidad se vea incrementado en el sector donde está insertado el mall. 
Lejos de constituir una arquitectura cerrada, enfocada únicamente en el consumo, el Quicentro busca relacionarse con la ciudad y configurar espacios de sociabilidad y encuentro, características que lo convierte en un modelo singular de shopping center que los usuarios no solo visitan en busca del consumo de bienes, sino en busca de la ocupación y apropiación de espacios para la creación de experiencias colectivas e individuales.

Las características espaciales y programáticas (permanentes, temporales, cotidianas y especiales) han convertido al Quicentro en un nodo urbano que alberga un alto grado de diversidad de actividades adicionales a las de consumo: culturales, artísticas, educativas, de entretenimiento, de servicios y de ocio; y lo han afianzado como espacio de reunión, sociabilidad y encuentro.

El Quicentro Shopping Center ha sabido adaptarse a las nuevas necesidades que le exige la sociedad y ampliar su público, atrayéndolo mediante mutaciones morfológicas y construyendo cada vez más espacios de encuentro colectivo donde se desarrollan diferentes actividades. Ha logrado, de esta forma, congregar funciones de los espacios públicos de Quito, configurando lugares que son una extensión de la ciudad. Ello ha provocado que los usuarios lo consideren un espacio público (sobre todo, a los espacios donde se llevan a cabo eventos colectivos) que tiene diversidad de usos y usuarios, un fácil acceso, y que permite el desarrollo de una amplia gama de actividades y situaciones (Jacobs, 2016), alrededor de las cuales se han modelado los locales para el consumo.

EI QSC ha desempeñado un rol diferente al del modelo suburbano norteamericano: ha adaptado a su espacialidad y programa a la cultura local, empezando por su concepción en 1980 (Michel Deller ${ }^{4}$ ) y siguiendo, luego, con su posterior construcción en 1982, estratégicamente emplazada en un terreno localizado en un sector pericentral, en vías de desarrollo, de la de ciudad Quito y concebido como el centro financiero de la ciudad y del país. En su entorno se consolidaron proyectos de vivienda, comercio y servicios en menos de diez años, que apuntalaron su papel de nodo urbano.

Ha existido siempre una intensa dialéctica entre el QSC y su entorno. En esa dirección, la ciudad se ha transformado no para superponerse con las funciones del shopping center sino para complementarlas y volverse "competitiva" (De Simone, 2015). Al mismo tiempo, el QSC ha tenido que mutar rápidamente (mayor permeabilidad en su fachada e ingresos y mayor área para el encuentro y la sociabilidad) con miras a adaptarse a las nuevas necesidades, espaciales y programáticas de los usuarios y no perder su jerarquía urbana. A partir de la "permeabilización" de la fachada hacia la ciudad, las actividades del QSC desarrolladas hacia el exterior (espacio público) han resultado más rentables (Michel Deller, comunicación personal, enero de 2016) que antes de su transformación en 2012, gracias al diálogo que ha incentivado con la ciudad y a su fácil acceso.

Adicionalmente a la discusión global que envuelve el tema del shopping center, en Quito y en el Ecuador, en general, éste no ha sido un tema de debate científico, motivo por el cual se considera importante que los académicos tomemos la oportunidad de estudiarlo con su singularidad espacial y programática en un medio con componentes geográficos, políticos,

4 Entrevista con acuerdo de confidencialidad, enero de 2016. 
sociales, ideológicos, culturales, económicos e históricos específicos, como lo es una capital de Latinoamérica.

\subsection{El rol del Quicentro Shopping Center en la planificación, construcción y apropiación de Quito. Discusión de los resultados.}

El shopping center, desde que fuera concebido en 1954 por Victor Gruen, fue planteado como una unidad de planificación urbana en la que estos complejos comerciales atraerían flujos, permanencias y jerarquías que serían plasmados espacialmente en el territorio. Gruen también consideró necesaria la descentralización de las ciudades, para lo cual se debía planificar estratégicamente shopping centers en las periferias que vendrían a convertirse en los nuevos polos de atracción de diversas actividades y formas de entretenimiento de la ciudad (Gruen, 1964). Sin embargo, este modelo de Gruen no fue ejecutado según lo propuesto y se insertaron shopping centers en suburbios residenciales norteamericanos extensos, como elementos aislados del territorio. En la actualidad, se puede verificar con el estudio del QSC y otros shopping centers de Quito, que parte de la idea o concepto original se ha materializado en la ciudad.

En concreto, el QSC en Quito, fue concebido como un detonante de activación y consolidación urbanística. Este shopping center, a pesar de no ser mencionado en sí como un elemento de la planificación del gobierno local, fue claramente insertado en un terreno planificado como equipamiento comercial con el fin de activar un sector concebido como el centro financiero de Quito.

Así, el QSC está vinculado con la forma en la que se ha construido la ciudad y se ha consolidado el sector Iñaquito. Tal como se pudo observar en el análisis gráfico presentado, la inserción del QSC estuvo acompañada de transformaciones del uso del suelo a múltiple, del incremento a la accesibilidad al transporte público, el incremento de la densidad y la edificabilidad, provocando una mayor intensidad, concentración y diversidad de situaciones y actividades, tanto en el espacio privado como en el espacio público del mencionado sector.

De modo similar, se evidenció que el QSC se inserta en una pieza urbana planificada con estrategias de desarrollo. En efecto, el territorio "recibe" al QSC como parte importante de sus estrategias de activación y consolidación del sector. Posteriormente, el shopping center detona algunas dinámicas que, si bien no fueron planificadas activaron más el espacio urbano, fortaleciendo la relación del QSC y de los edificios de su entorno con el espacio público.

Rebatiendo el discurso detractor del shopping center, en el entorno del QSC el comercio local ha aumentado y ha ocasionado una convivencia entre ese tipo de comercio y el propio del shopping center, generando una superposición de formas comerciales en un polo de centralidad de la ciudad. En este sentido, es vital resaltar que el shopping center no ha "aniquilado" (Sarlo, 2009) o reemplazado a la ciudad, sino que ha venido a convertirse en una prolongación de la misma.

Por otra parte, el transporte público proyectado refleja que se ha procurado la articulación de este polo de atracción de la ciudad, planificado como centralidad urbana, para incrementar su accesibilidad: BRT'S, bicicleta urbana, autobuses de línea y el metro. 
Debe subrayarse que en el entorno del Quicentro, la densidad propuesta aumenta al igual que el uso de suelo múltiple. La edificabilidad y zonificación propuestas también facilitan la relación de las edificaciones con el espacio público. La diversidad de formas (obtenidas por la edificabilidad, formas de ocupación y zonificación planificadas) y de usos concentrados en el sector de Iñaquito, donde se inserta el QSC, han contribuido con la aglomeración de diferentes tipos de usuarios, provocando la consolidación de Iñaquito como el centro financiero de Quito y el espacio con el mayor grado de centralidad de la ciudad, tal como fue concebido en los planes.

A partir del análisis gráfico expuesto en este trabajo, se ha evidenciado que el grado de centralidad de esta pieza urbana planificada y construida puede ser medible y cuantificable en términos del uso de suelo, la densidad, el transporte, la edificabilidad y la zonificación (Panerai, 2006; Hassenpflug, 2007; Vidal y Pol, 2005; Brandão, 2002; Santos y Voguel, 1985), puesto que tales variables son herramientas que funcionan como indicadores de concentración, intensidad y diversidad de usos, usuarios y horarios.

De acuerdo a la observación y participación como usuario in situ y a los resultados de las encuestas realizadas, únicamente un $20 \%$ de las personas que visitan el Quicentro lo hace con la intención de comprar. El 80\% restante busca encontrarse con otras personas, entretenerse, pasear y vitrinear (De Simone, 2015). Estas actividades de sociabilidad, de todas maneras, benefician al shopping center puesto que la gente se alimenta o compra bebidas y paga el estacionamiento y "todos salen ganando" (Michel Deller, comunicación personal, enero de 2016).

El mismo Quicentro se ha debido transformar para buscar una mayor relación con su entorno y captar la mayor cantidad de usuarios posible (siempre en aras de que se consuma al menos algo con cada una de las 150 mil visitas diarias), ya sean estas transformaciones en su forma y materialidad, como en sus usos y en las actividades adicionales a las ventas y servicios de los locales. Cualquier modificación que se realice en el Quicentro puede detonar, a su vez, cambios en la ciudad.

La "espalda" o fachada norte del Quicentro, que restringe una relación directa con la ciudad, coincide con el menor desarrollo de su entorno norte, a pesar de que, en la planificación, las manchas de uso de suelo, densidad y el acceso al transporte, mantienen un equilibrio con lo planteado para el entorno sur.

Finalmente, como resultado general de esta investigación, se concluye que los shopping centers no siempre son "cajas herméticas", cerradas, que aniquilan al espacio público, que niegan a la ciudad y se encuentran desarticuladas de la misma. Por el contrario, como ha sido demostrado este análisis del espacio concebido, construido y vivido del Quicentro Shopping Center y el sector donde se inserta, existe una intensa dialéctica shopping center - ciudad, la cual evidencia la capacidad de estas arquitecturas de ser elementos permeables que complementan la ciudad, se enlazan y prolongan el espacio público, incentivando la apropiación de la ciudad. 


\subsection{Consideraciones finales para futuras investigaciones sobre el shopping center}

Este trabajo de tesis aspira a ser una contribución a la narrativa académica acerca de los shopping centers, que aporte al conocimiento científico y permita la ampliación de la discusión y el debate sobre esta apasionante temática.

La figura del Quicentro Shopping Center podría ser utilizada como un modelo de planificación y reactivación urbana dadas las transformaciones exitosas que se han planificado y ejecutado en paralelo a su inserción. No obstante, es sin duda importante incorporar a estos estudios la perspectiva antropológica y sociológica, vinculada a la dimensión del consumo de masas, antes de asumir dicho modelo como una "respuesta" unívoca a la reactivación urbana. Se considera fundamental, desde esta óptica, trabajar con un equipo multidisciplinario para poder afirmar o negar la influencia real que provoca esta arquitectura, no solo a partir de la forma y usos de la ciudad. De modo que la labor llevada a cabo en esta investigación es absolutamente susceptible de ser complementada.

Así también, es necesario realizar estudios multiescalares y multidisciplinarios de estos objetos urbano-arquitectónicos, despojados de prejuicios ideológicos y posturas ortodoxas, ya que más allá de las críticas estigmatizantes hacia el shopping center, los datos revelan, en este caso, que -de forma opuesta a lo planteado por los críticos del shopping-, constituyen elementos importantes de considerarse en la planificación, construcción y apropiación de la ciudad.

Como última reflexión, vale mencionar que luego de realizar el análisis gráfico de esta investigación, y de su confrontación con las dos aproximaciones teóricas al shopping center revisadas, se considera fundamental que los estudios de cada una de estas arquitecturas sean elaborados de forma detallada, prolija y en sintonía con sus características específicas, como el de cualquier otro espacio arquitectónico o urbanístico, porque no se puede generalizar las transformaciones que cada shopping pueda originar en diferentes momentos históricos y contextos geográficos, culturales, políticos, sociales, económicos y tecnológicos. Analizarlos de forma genérica sería, pues, impreciso y sin fundamento científico.

\section{Bibliografía}

ASCHER, F. Los nuevos principios del urbanismo. Madrid, Alianza, 2004. 93 p.

BAUMAN, Z. Trabajo, consumismo y nuevos pobres. Barcelona, Gedisa, 2000. 154 p.

BAUDRILLARD, J. The Consumer Society. London, Sage, 1998. 208 p.

BELL, D. Las contradicciones culturales del capitalismo. Madrid, Alianza, 2006. 264 p.

BENTO, P. Los nuevos lugares de la colectividad. Los espacios de Consumo y Ocio. En: QRU: Quaderns de Recerca en Urbanisme [en línea]. Junio 2011, núm. 1, pp. 58-74. [Fecha de consulta: 28 de junio de 2017]. ISSN 2014-9689. Disponible en: $<$ https://upcommons.upc.edu/bitstream/handle/2099/16020/06_PedroBento.pdf>. 
BORJA, J y MUXÍ, Z. El espacio público: ciudad y ciudadanía. 2da. Ed. Barcelona, Electa, 2003. $118 p$.

BORJA, J. La ciudad conquistada. Madrid, Alianza, 2003. 381 p.

BORJA, J. La ciudad del deseo. En: Quaderns d'arquitectura i urbanisme [en línea]. 2002, núm. 235, pp. 20-24. [fecha de consulta: 28 de junio de 2017]. ISSN 1133-885. Disponible en: <https://www.raco.cat/index.php/QuadernsArquitecturaUrbanisme/issue/view/17598/showToc>

BORJA, J. Ciutat real, ciutat ideal. Significat i funció a l'espai urbà modern. Barcelona, Centre de Cultura Contemporània, 1998.

BRANDÃO, Z. O papel do desenho urbano no planejamento estratégico: a nova postura do arquiteto no plano urbano contemporâneo. En: Arquitextos [en línea]. 2002, núm. 025. [Fecha de consulta: 01 de junio de 2017]. ISSN 1809-6298. Disponible en: <http://www.vitruvius.com.br/revistas/read/arquitextos/03.025/7733>

CÁCERES, G. et al. Malls en Santiago: luces y claroscuros. En: $\underline{A R Q}$ [en línea]. 2006, núm. 62, pp. 48-53. [Fecha de consulta: 28 de junio de 2017]. ISSN 0717-6996. Disponible en: <http://www.scielo.cl/pdf/arq/n62/art09.pdf>

CAPRON, G., SABATIER, B. Identidades urbanas y culturas públicas en la globalización. Centros comerciales paisajísticos en Río de Janeiro y México. En: Alteridades [en línea]. 2007, vol. 17, núm. 33, pp. 87-97. [Fecha de consulta 01 de junio de 2017]. Disponible en: $<$ http://www.redalyc.org/pdf/747/74712772008.pdf>. ISSN 0188-7017

CARRIÓN, F. Centralidad y plazas. Quito: En: Diario Hoy [en línea]. 2010. [Fecha de consulta: 28 de junio de 2017]. Disponible en: <https://works.bepress.com/fernando_carrion/379/>

COLLIN DEVALAND, A. Quito, La Ciudad del Volcán. Quito, Libri Mundi/Enrique GrosseLuermern, 2002. $245 \mathrm{p}$.

CHUNG, C. et al. Harvard Design School guide to shopping / Project on the City 2. Colonia, Taschen, 2001. $800 \mathrm{p}$.

CRAWFORD, M. Everyday Urbanism: Michigan Debates on Urbanism I. Michigan, University of Michigan, 1999. $75 \mathrm{p}$.

DE SOLÀ-MORALES, M. Espacios públicos / Espacios colectivos. En: La Vanguardia [en línea]. 1992. [fecha de consulta: 28 de junio de 2017]. Disponible en: <http://www.cafedelasciudades.com.ar/carajillo/5_art3.htm>

DELGADO, M. y MALET, D. El Espacio Público como Ideología. En: Fórum Español para la Prevención y la Seguridad Urbana (FEPSU) - URBANDOCS [en línea]. 2013. [fecha de consulta: 28 de junio de 2017]. Disponible en: <http://www.fepsu.es/docs/urbandocs/URBANDOC1.pdf>

ACEO AÑO 14, núm. 40, JUNIO 2019 | TRANSFORMACIONES DE LA CIUDAD Y EL SHOPPING CENTER - ANÁLISIS EN LA ESCALA 312 DEL SECTOR DE IÑAQUITO Y EL QUICENTRO SHOPPING CENTER EN QUITO 
DO AMARAL E SILVA, G. y ASSEN DE OLIVEIRA, L. Arquitetura da cidade contemporânea: sobre raízes, ritmos e caminhos. Florianópolis, Editora da UFSC, 2013. 335 p.

DUPUY, G. El urbanismo de redes: teorías y métodos. Madrid, Oikos-Tau, 1998. 215 p.

ELLIN, N. Integral Urbanism. Ney York, Routledge, 2006. 193 p.

GRUEN, V. The Heart of Our Cities: The Urban Crisis, Diagnosis and Cure. New York, Simon And Schuster, 1964. 368 p.

HARVEY, D. La condición de la posmodernidad. Investigación sobre los orígenes del cambio cultural. Buenos Aires, Amorrortu, 2004. 401 p.

HASSENPFLUG, D. Sobre centralidade urbana. En: Arquitextos [en línea]. 2007, no.085. [fecha de consulta: 01 de junio de 2017]. Disponible en: <http://www.vitruvius.com.br/revistas/read/arquitextos/08.085/235>. ISSN 1809-6298

LEFEBVRE, H. The Production of Space. New Jersey, Wiley-Blackwell, 2000. 454 p.

LIPOVETSKY, G. La felicidad paradójica. Ensayo sobre la sociedad de hiperconsumo. Barcelona, Anagrama, 2007. 416 p.

LÓPEZ LEVI, L. Centros comerciales. Espacios que navegan entre la realidad y la ficción. Ciudad de México, Nuestro Tiempo, 1999. 241 p.

LULLE, T. y PAQUETTE, C. Los grandes centros comerciales y la planificación urbana. Un análisis comparativo de dos metrópolis latinoamericanas. En: Revista de Estudios demográficos y urbanos. 2007, vol. 22, núm. 2, pp. 337-361.

MUNICIPIO DE QUITO. Plan Regulador de Quito. Quito, Imprenta municipal, 1940. 195 p.

MUNICIPIO DE QUITO. Plan Director de Urbanismo de San Francisco de Quito. Quito, Imprenta Municipal, 1967. $82 \mathrm{p}$.

MUNICIPIO DE QUITO. Quito y su área Metropolitana: Plan Director 1973 - 1993. Quito, s.n., 1973. $67 \mathrm{p}$.

MUNICIPIO DE QUITO. Plan Quito. Quito, IMQ, 1980.640 p.

MUNICIPIO DE QUITO. Plan de Estructura Urbana de Quito. Quito, s.n., 1990. 123 p. 96 p.

MUNICIPIO DE QUITO. Plan General de Desarrollo Territorial 2000 - 2020. Quito, Imprenta Municipal, 2001. $216 \mathrm{p}$.

MUNICIPIO DE QUITO. Plan Equinoccio 21: Quito hacia el 2025 - Plan Estratégico del DMQ. Quito, s.n., 2001. 301 p.

ACEO AÑO 14, núm. 40, JUNIO 2019 | TRANSFORMACIONES DE LA CIUDAD Y EL SHOPPING CENTER - ANÁLISIS EN LA ESCALA 313 DEL SECTOR DE IÑAQUITO Y EL QUICENTRO SHOPPING CENTER EN QUITO 
MUNICIPIO DE QUITO. Plan Metropolitano de Ordenamiento Territorial 2012 - 2022. Quito, Imprenta Municipal, 2012. $84 \mathrm{p}$.

MUNICIPIO DE QUITO. Plan de Desarrollo y de Ordenamiento Territorial. Quito, MDMQ, 2015. $312 \mathrm{p}$.

NAPADENSKY, A. y RIVERA, F. Espacios genéricos y apropiaciones sociales en centros comerciales: El caso del Mall Plaza del Trébol en el área metropolitana de Concepción, 19942012. En: Urbano [en línea]. 2015, núm. 31, pp. 32-51. [Fecha de consulta: 28 de junio de 2017]. Disponible en: <http://revistas.ubiobio.cl/index.php/RU/article/view/1064>. ISSN 07173997 / O718-3607

NAPADENSKY, A. Apocalípticos, optimistas y neutrales; discursivas académicas en torno a los shopping mall. El caso del Mall Plaza del Trébol, Área Metropolitana de Concepción, Chile. En: International Congress of Americanists - Conflicto, paz y construcción de identidades en las Américas $\left(55^{\circ}, 2015\right.$, San Salvador, El Salvador).

NAPADENSKY, A. Mall Parque Arauco: La arquitectura de una nueva urbanidad. Contexto, concepción y percepción de una transformación. 1979-2009. Tesis doctoral inédita, Pontificia Universidad Católica de Chile, 2012.

PANERAI, P. Análise Urbana. Brasilia, Editora Universidade de Brasilia, 2006. 198 p.

PAQUETTE, C. Comercio y planificación urbana. Las nuevas grandes centralidades comerciales en los planos de desarrollo urbano de la Ciudad de México. En: Trace: Comercio y Políticas Públicas [en línea]. 2007, núm. 51, pp. 44-55. [fecha de consulta: 01 de junio de 2017]. Disponible en: <http://journals.openedition.org/trace/641>. ISBN 0185-6286

ROSSI, A. La arquitectura de la ciudad. Barcelona, Gustavo Gili, 2007. 200 p.

SALCEDO, R. Lo local, lo global y el mall: la lógica de la exclusión y la interdependencia. En: Revista de Geografía Norte Grande [en línea]. 2003, núm. 30, pp. 103-115. [Fecha de consulta: 28 de junio de 2017]. Disponible en: <https://repositorio.uc.cl/bitstream/handle/11534/10464/000371833.pdf>

SANDIKCI, O. y HOLT, D. Malling society: Mall consumption practices and the future of public space. En: ServiceScapes: The concept of place in contemporary markets, 305-336, 1998.

SANTOS, C., VOGEL, A. Quando a rua vira casa. Apropriação de espaços de uso coletivo em um centro de bairro. São Paulo, Projeto, 1985. 174 p.

SARLO, B. La ciudad Vista: Mercancías y cultura urbana. Buenos Aires, Siglo XXI, 2009. 232 p.

SARLO, B. Escenas de la vida posmoderna. Buenos Aires, Seix Barral, 1994. 226 p.

SARLO, B. Tiempo Presente: notas sobre el cambio de una cultura. Buenos Aires, Siglo XXI, 2006. $238 \mathrm{p}$.

ACEO AÑO 14, núm. 40, JUNIO 2019 | TRANSFORMACIONES DE LA CIUDAD Y EL SHOPPING CENTER - ANÁLISIS EN LA ESCALA 314 DEL SECTOR DE IÑAQUITO Y EL QUICENTRO SHOPPING CENTER EN QUITO 
SOJA, E. Third space. Journeys to Los Angeles and other real-and-imagined places. Massachusetts, Blackwell, 2000. 348 p.

SECCHI, B. La ciudad de los ricos y la ciudad de los pobres. Madrid, Catarata, 2013. 91 p.

SENNETT, R. El declive del hombre público. Barcelona, Península, 2002. 464 p.

SENNETT, R. La cultura del nuevo capitalismo. Barcelona, Anagrama, 2006. 185 p.

SORKIN, M. Variaciones sobre un parque temático: la nueva ciudad americana y el fin del espacio público. Barcelona, Gustavo Gili, 2004. 258 p.

STILLERMAN, J. y SALCEDO, R. Es mucho más que comprar... Discursos y practicas espaciales cotidianas en Malls de Santiago. En: Estudios Avanzados [en línea]. 2010, núm. 13, pp. 79-103. [Fecha de consulta: 01 de junio de 2017] Disponible en: <http://www.revistas.usach.cl/ojs/index.php/ideas/article/view/127>

URTEAGA, M. y CORNEJO, I. La privatización afectiva de los espacios comerciales por las y los jóvenes. En: Ciudades. Núm. 27, pp. 24-28, 1995.

VIDAL, T. y POL, E. La apropiación del espacio: una propuesta teórica para comprender la vinculación entre las personas y los lugares. En: Anuario de Psicología [en línea]. 2005, vol.36, no.3: 281-297. [Fecha de consulta: 01 de junio de 2017]. Disponible en: <https://www.raco.cat/index.php/AnuarioPsicologia/article/view/61819>

WALL, A. Victor Gruen: From Urban Shop To New City. New York, Acta, 2005. 267 p.

ACEO AÑO 14, núm. 40, JUNIO 2019 | TRANSFORMACIONES DE LA CIUDAD Y EL SHOPPING CENTER - ANÁLISIS EN LA ESCALA 315 DEL SECTOR DE IÑAQUITO Y EL QUICENTRO SHOPPING CENTER EN QUITO 